\title{
UK Renal Registry 15th Annual Report: Chapter 1 UK RRT Incidence in 2011: National and Centre-Specific Analyses
}

\author{
Julie Gilg ${ }^{a}$, Anirudh Rao ${ }^{a}$, Damian Fogarty ${ }^{\mathrm{ab}}$ \\ ${ }^{\mathrm{a} U K}$ Renal Registry, Bristol, UK; ${ }^{\mathrm{b}}$ Queens University, Belfast, UK
}

\section{Key Words}

Acceptance rates · Comorbidity · Dialysis - End stage renal disease - End stage renal failure - Established renal failure - Haemodialysis - Incidence - Peritoneal dialysis - Primary Care Trust - Renal replacement therapy - Transplantation . Treatment modality

\footnotetext{
Abstract

Introduction: This chapter describes the characteristics of adult patients starting renal replacement therapy (RRT) in the UK in 2011 and the incidence rates for RRT in Primary Care Trusts and Health Boards (PCT/HBs) in the UK. Methods: Basic demographic and clinical characteristics are reported on patients starting RRT at all UK renal centres. Presentation time, defined as time between first being seen by a nephrologist and start of RRT, was also studied. Age and gender standardised ratios for incidence rates in PCT/HBs were also calculated. Results: In 2011, the incidence rate in the UK was similar to 2010 at 108 per million population (pmp). There were wide variations between PCT/HBs in
}

standardised incidence ratios. For the 2006-2011 incident cohort analysis the range was 0.42 to 2.52 (IQR $0.85,1.20$ ). The median age of all incident patients was 64.9 years (IQR 50.9, 75.1). For transplant centres this was 63.8 years (IQR 49.5, 74.3) and for non-transplanting centres 66.2 years (IQR 52.4, 76.0). The median age for non-Whites was 58.4 years. Diabetic renal disease remained the single most common cause of renal failure $(25 \%)$. By 90 days, $67.1 \%$ of patients were on haemodialysis, $19.2 \%$ on peritoneal dialysis, 7.8\% had had a transplant and $5.8 \%$ had died or stopped treatment. This is the second year in a row that the percentage on peritoneal dialysis has increased and, in 2011 , this was most notable in the $65-74$ age group. There was a lot of variability in use of PD with some centres having over twice the average percentage on PD. The mean eGFR at the start of RRT was $8.7 \mathrm{ml} / \mathrm{min} / 1.73 \mathrm{~m}^{2}$ similar to the previous four years. Late presentation ( $<90$ days) fell from $23.9 \%$ in 2006 to $19.6 \%$ in 2011 . There was no relationship between social deprivation and presentation pattern. Conclusions: Incidence rates have plateaued in England over the last six years. There has been an increase in the percentage of new patients still on RRT at 90 days after starting who were on PD at 90 days (19.2 to 20.4\%).

$\begin{array}{ll}\text { KARGER } & \text { C } 2013 \mathrm{~S} . \text { Karger AG, Basel } \\ \text { Fax +4161306 1234 } & 1160-2110 / 13 / 1235-0001 \$ 38.00 / 0 \\ \begin{array}{l}\text { E-Mail karger@karger.ch } \\ \text { www.karger.com }\end{array} & \begin{array}{l}\text { Accessible online at: } \\ \text { www.karger.com/nec }\end{array}\end{array}$




\section{Introduction}

This chapter contains analyses of adult patients starting renal replacement therapy (RRT) in the UK in 2011. It describes regional and national variations in incidence rates of RRT, the demographic and clinical characteristics of all patients starting RRT and analyses of late presentation and delayed referral. The methodology and results for these analyses are in three separate sections.

\section{Definitions}

The definition of incident patients is given in detail in appendix B: Definitions and Analysis Criteria (www. renalreg.com). In brief, it is all patients over 18 who commenced RRT in the UK in 2011 and who did not recover renal function within 90 days: this does not include those with a failed renal transplant who returned to dialysis (as they had already started RRT).

Differences may be seen in the 2006 to 2010 numbers now quoted when compared with previous publications because of retrospective updating of data in collaboration with renal centres, in particular for patients who were initially thought to have acute renal failure. Where applicable and possible, pre-emptive transplant patients were allocated to their work up centre rather than their transplant centre. However, this was not possible for all such patients and consequently some patients probably remain incorrectly allocated to the transplanting centre.

The term established renal failure (ERF) used within this chapter is synonymous with the terms end stage renal failure (ESRF) and end stage renal disease (ESRD) which are in more widespread international usage. Patient groups have disliked the term 'end stage' which reflected the inevitable outcome of this disease.

\section{UK Renal Registry coverage}

The UK Renal Registry (UKRR) received individual patient level data from all 71 adult renal centres in the UK (five renal centres in Wales, five in Northern Ireland, nine in Scotland, 52 in England). Hope Hospital has been renamed Salford Royal and so is now abbreviated in the report as 'Salford' rather than as 'M Hope'. There are only five Northern Irish centres in the report this year as 'Tyrone' and 'Derry' are now grouped together as 'West NI'. Data from centres in Scotland were obtained from the Scottish Renal Registry. Data on children and young adults can be found in chapter 4: Demography of the UK Paediatric Renal Replacement Therapy population in 2011 .

\section{Geographical variation in incidence rates}

Over the years, there have been wide variations in incidence rates between renal centres. Equity of access to RRT is an important aim but hard to assess as the need for RRT depends on many variables including medical, social and demographic factors such as underlying conditions, age, gender, social deprivation and ethnicity. Thus, comparison of crude incidence rates by geographical area can be misleading. This year's report again uses age and gender standardisation as well as showing crude rates. It also gives the ethnic minority percentage of each area as this influences incidence rates. More detailed analyses at the Registry investigated the effect of socio-demographic, population health status and access to care factors on RRT incidence. These suggested that population age, socio-economic deprivation and the proportion of non-White residents were able to explain $22 \%$ of the observed variation in RRT incidence. The prevalence of diabetes in an area explained a further $4 \%$ of the variation and access to complex health procedures (CABG/coronary angioplasty) a further $6 \%$ [1]. Despite accounting for all these factors much of the observed variation remains unexplained and is thought to be due to practice patterns in place at individual renal centres.

Methods

Crude incidence rates were calculated per million population (pmp) and age/gender standardised incidence ratios were calculated as detailed in appendix D: Methodology used for Analyses (www.renalreg.com).

\section{Results}

In 2011, the number of adult patients starting RRT in the UK was 6,835 equating to an incidence rate of 108 pmp (table 1.1), slightly higher than in 2010. Wales remained the country with the highest incidence rate although the rate has fallen since 2006 and in 2011 was closer to the UK average (figure 1.1). For England, incidence rates have been stable for the last 6 years. There continued to be very marked gender differences in incidence rates which were $139 \mathrm{pmp}$ (95\% CI 135 143 ) in males and $79 \mathrm{pmp}$ (95\% CI 76-82) in females. When incident patients aged under 18 were included, the UK rate was $110 \mathrm{pmp}$.

Table 1.2 shows incidence rates and standardised incidence ratios for PCT/HBs. The ratios calculated using combined data from up to six years have been used to determine areas with significantly high or low 
Table 1.1. Number of new adult patients starting RRT in the UK in 2011

\begin{tabular}{lccccc}
\hline & England & N Ireland & Scotland & Wales & UK \\
\hline Number starting RRT & 5,774 & 203 & 495 & 363 & $\mathbf{6 , 8 3 5}$ \\
Total estimated population mid-2011 (millions) & 53.0 & 1.8 & 5.3 & 3.1 & $\mathbf{6 3 . 2}$ \\
Incidence rate (pmp) & 109 & 112 & 93 & 118 & $\mathbf{1 0 8}$ \\
$(95 \%$ CI) & $(106-112)$ & $(97-128)$ & $(85-102)$ & $(106-131)$ & $(\mathbf{1 0 6}-\mathbf{1 1 1})$ \\
\hline
\end{tabular}

${ }^{\star}$ Data from the Office for National Statistics - based on the 2011 census.

incidence rates. Significantly high areas have been shaded with bold text and significantly low areas shaded a lighter grey with italicised text. There were wide variations between areas, with 53 being significantly high and 48 being significantly low out of a total of 177 areas. Last year these numbers were 52 and 54 areas respectively. The standardised incidence ratios ranged from 0.42 to 2.52 (IQR 0.85, 1.20).

As would be expected, urban areas with high percentages of non-White residents tended to have high incidence rates. Figure 1.2 shows the positive correlation $(\mathrm{r}=0.84, \mathrm{p}<0.001)$ between the standardised incidence ratio and the percentage of the $\mathrm{PCT} / \mathrm{HB}$ population that was non-White.

Confidence intervals are not presented for the crude rates per million population but figures D1 and D2 in appendix D can be used to determine if a PCT/HB falls within the 95\% confidence interval around the national average rate.

The number of new patients starting RRT at each renal centre from 2006 to 2011 is shown in table 1.3. For most centres there was a lot of variability in the numbers of

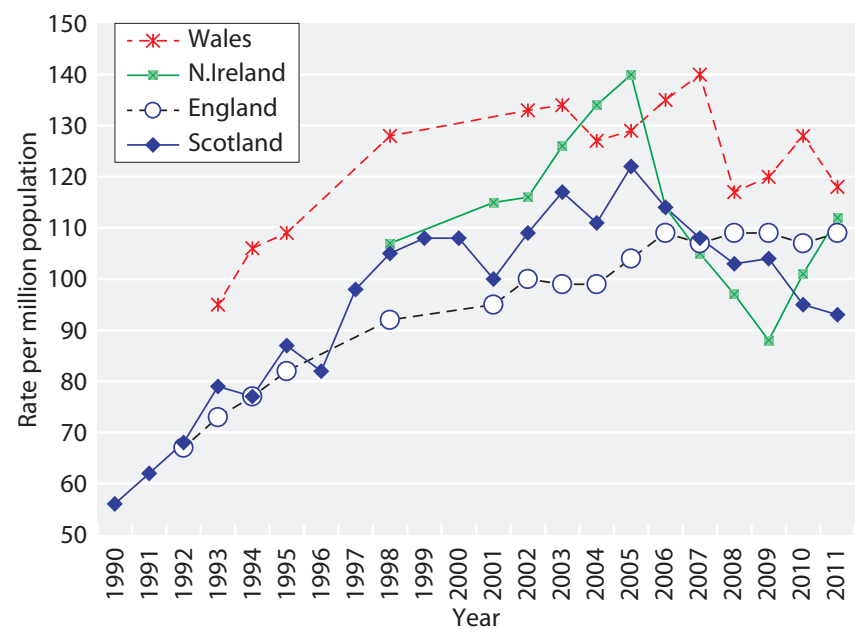

Fig. 1.1. RRT incidence rates in the countries of the UK 19902011 incident patients from one year to the next making it harder to see any underlying trend. Some centres have had an increase in new patients over time and others have fallen. The variation may reflect chance fluctuation, the introduction of new centres, changes in catchment populations or in completeness of reporting. Variation over time may also be due to changing incidence of established renal failure (increases in underlying disease prevalence, survival from co-morbid conditions and recognition of ERF), changes to treatment thresholds or the introduction of conservative care programmes. Centre level incidence rates (per million population) were presented for the first time in the 13th Annual Report (www.renalreg.com) after a piece of work was done to estimate the English centres' catchment populations (using 2007 prevalent dialysis patients). These rates are again reported this year. For a description of the methodology used to estimate the catchment populations and discussion of some limitations see appendix E: Methodology for Estimating Catchment Populations Analyses (www.renalreg.com). Estimates of the catchment populations in Wales, Northern Ireland and Scotland were supplied by personal communication from Dr K Donovan, Dr A Williams, Dr D Fogarty and the Scottish Renal Registry.

There were falls of over $10 \%$ in the number of new patients for Scotland and Wales from 2007 to 2011. There was an increase of about 5\% in new patients for England and 8\% for Northern Ireland from 2007 to 2011. Across all four countries the change from 2007 to 2011 was an increase of $2.5 \%$.

\section{Demographics and clinical characteristics of patients starting RRT}

\section{Methods}

Age, gender, primary renal disease, ethnic origin and treatment modality were examined for patients starting RRT. Centre level 
Table 1.2. Crude adult incidence rates (pmp) and age/gender standardised incidence ratios 2006-2011

PCT/HB - PCT in England, Health and Social Care Areas in Northern Ireland, Local Health Boards in Wales and Health Boards in Scotland $\mathrm{O} / \mathrm{E}$ - standardised incidence ratio

LCL - lower 95\% confidence limit

UCL - upper 95\% confidence limit

pmp - per million population

${ }^{\star}$ - per year

Areas with significantly low incidence ratios over six years are italicised in greyed areas, those with significantly high incidence ratios over six years are bold in greyed areas

Blank cells - no data returned to the UKRR for that year

$\%$ non-White - percentage of the PCT/HB population that is non-White, from 2001 census (revised by ONS to 2007 for England)

For those areas not covered by the Registry for the entire period 2006-2011, the combined years standardised incidence ratios and incidence rates are averages for the years covered by the registry

\begin{tabular}{|c|c|c|c|c|c|c|c|c|c|c|c|c|c|c|}
\hline UK Area & PCT/HB & $\begin{array}{l}\text { Tot pop } \\
(2010)\end{array}$ & $\begin{array}{c}2006 \\
\mathrm{O} / \mathrm{E}\end{array}$ & $\begin{array}{r}2007 \\
\mathrm{O} / \mathrm{E}\end{array}$ & $\begin{array}{l}2008 \\
\mathrm{O} / \mathrm{E}\end{array}$ & $\begin{array}{l}2009 \\
\mathrm{O} / \mathrm{E}\end{array}$ & $\begin{array}{l}2010 \\
\mathrm{O} / \mathrm{E}\end{array}$ & $\mathrm{O} / \mathrm{E}$ & $\begin{array}{l}1 \\
\text { Crude } \\
\text { rate } \\
\text { pmp }\end{array}$ & $\mathrm{O} / \mathrm{E}$ & $\begin{array}{l}95 \% \\
\text { LCL }\end{array}$ & $\begin{array}{l}95 \% \\
\text { UCL }\end{array}$ & $\begin{array}{c}\text { Crude } \\
\text { rate } \\
\text { pmp }^{*}\end{array}$ & $\begin{array}{c}\% \\
\text { non- } \\
\text { White }\end{array}$ \\
\hline \multirow{12}{*}{$\begin{array}{l}\text { North } \\
\text { East }\end{array}$} & County Durham & 510,800 & 0.88 & 0.67 & 0.69 & 0.76 & 0.78 & 0.83 & 96 & 0.77 & 0.68 & 0.87 & 88 & 2.5 \\
\hline & Darlington & 100,600 & 0.62 & 1.16 & 1.07 & 0.96 & 0.99 & 0.96 & 109 & 0.96 & 0.75 & 1.22 & 108 & 3.3 \\
\hline & Gateshead & 192,000 & 0.91 & 0.78 & 0.55 & 0.86 & 0.79 & 0.81 & 94 & 0.78 & 0.65 & 0.95 & 89 & 3.8 \\
\hline & Hartlepool & 91,400 & 1.48 & 0.50 & 1.30 & 0.79 & 0.60 & 0.49 & 55 & 0.86 & 0.66 & 1.13 & 95 & 2.6 \\
\hline & Middlesbrough & 142,100 & 1.53 & 1.19 & 1.26 & 0.69 & 1.49 & 0.69 & 70 & 1.14 & 0.93 & 1.39 & 115 & 8.6 \\
\hline & Newcastle & 292,200 & 0.82 & 1.19 & 0.97 & 0.89 & 0.73 & 0.81 & 79 & 0.90 & 0.77 & 1.06 & 86 & 9.7 \\
\hline & North Tyneside & 198,400 & 0.79 & 0.76 & 0.49 & 0.92 & 0.99 & 0.61 & 71 & 0.76 & 0.63 & 0.92 & 87 & 3.6 \\
\hline & Northumberland & 312,100 & 0.71 & 0.75 & 0.67 & 0.61 & 0.62 & 0.84 & 106 & 0.70 & 0.60 & 0.82 & 88 & 2.2 \\
\hline & Redcar and Cleveland & 137,300 & 0.92 & 0.99 & 0.74 & 0.85 & 0.69 & 1.09 & 131 & 0.88 & 0.71 & 1.09 & 104 & 3.0 \\
\hline & South Tyneside & 154,100 & 1.08 & 1.15 & 0.58 & 1.25 & 0.70 & 0.96 & 110 & 0.95 & 0.78 & 1.16 & 108 & 4.8 \\
\hline & Stockton-on-Tees Teaching & 192,600 & 0.87 & 0.64 & 0.83 & 0.63 & 0.89 & 1.11 & 119 & 0.83 & 0.68 & 1.01 & 88 & 4.7 \\
\hline & Sunderland Teaching & 283,400 & 0.70 & 1.06 & 0.87 & 0.92 & 1.01 & 0.70 & 78 & 0.88 & 0.75 & 1.02 & 96 & 3.3 \\
\hline \multirow{24}{*}{$\begin{array}{l}\text { North } \\
\text { West }\end{array}$} & Ashton, Leigh and Wigan & 307,200 & 0.67 & 0.56 & 0.83 & 0.56 & 0.78 & 0.91 & 101 & 0.72 & 0.61 & 0.85 & 79 & 2.9 \\
\hline & Blackburn with Darwen Teaching & 140,000 & 1.29 & 1.31 & 0.54 & 0.91 & 1.09 & 1.51 & 143 & 1.11 & 0.90 & 1.37 & 104 & 22.7 \\
\hline & Blackpool & 140,200 & 0.54 & 0.98 & 0.92 & 0.96 & 0.61 & 0.90 & 107 & 0.82 & 0.66 & 1.02 & 96 & 3.7 \\
\hline & Bolton Teaching & 266,500 & 0.82 & 0.90 & 0.93 & 0.82 & 1.45 & 0.96 & 101 & 0.98 & 0.84 & 1.14 & 103 & 12.3 \\
\hline & Bury & 183,500 & 0.56 & 0.67 & 0.77 & 0.71 & 0.73 & 0.66 & 71 & 0.68 & 0.55 & 0.85 & 73 & 8.5 \\
\hline & Central and Eastern Cheshire & 457,200 & & 0.62 & 0.66 & 0.72 & 0.77 & 0.79 & 94 & 0.71 & 0.62 & 0.82 & 84 & 3.4 \\
\hline & Central Lancashire & 459,200 & 0.57 & 0.79 & 0.89 & 0.94 & 0.60 & 0.78 & 87 & 0.76 & 0.67 & 0.87 & 84 & 6.7 \\
\hline & Cumbria Teaching & 494,400 & 0.63 & 0.62 & 0.73 & 0.59 & 0.72 & 0.61 & 77 & 0.65 & 0.57 & 0.74 & 81 & 2.0 \\
\hline & East Lancashire Teaching & 381,200 & 0.94 & 0.73 & 0.66 & 0.84 & 0.71 & 0.88 & 97 & 0.79 & 0.69 & 0.91 & 86 & 9.4 \\
\hline & Halton and St Helens & 296,700 & 1.22 & 1.02 & 0.56 & 0.89 & 0.91 & 1.10 & 121 & 0.95 & 0.82 & 1.10 & 104 & 2.1 \\
\hline & $\begin{array}{l}\text { Heywood, Middleton and } \\
\text { Rochdale }\end{array}$ & 205,000 & & 0.91 & 1.01 & 1.13 & 0.82 & 1.22 & 127 & 1.02 & 0.84 & 1.23 & 104 & 12.6 \\
\hline & Knowsley & 149,200 & 0.89 & 1.03 & 0.52 & 0.76 & 0.91 & 1.08 & 114 & 0.87 & 0.70 & 1.08 & 90 & 2.8 \\
\hline & Liverpool & 445,300 & 1.20 & 1.12 & 1.16 & 1.22 & 0.97 & 1.27 & 128 & 1.16 & 1.03 & 1.29 & 115 & 8.3 \\
\hline & Manchester Teaching & 498,800 & & 1.24 & 1.28 & 1.41 & 1.31 & 1.26 & 102 & 1.30 & 1.15 & 1.47 & 103 & 23.4 \\
\hline & North Lancashire Teaching & 329,100 & 0.49 & 0.60 & 0.52 & 0.73 & 0.65 & 0.73 & 91 & 0.62 & 0.53 & 0.73 & 76 & 4.2 \\
\hline & Oldham & 219,600 & 0.85 & 0.90 & 1.09 & 0.89 & 0.92 & 0.98 & 100 & 0.94 & 0.79 & 1.12 & 95 & 12.2 \\
\hline & Salford & 229,100 & 0.96 & 0.62 & 1.01 & 1.00 & 1.34 & 0.69 & 70 & 0.94 & 0.79 & 1.11 & 93 & 7.7 \\
\hline & Sefton & 272,800 & 0.78 & 0.55 & 0.88 & 0.77 & 1.01 & 1.45 & 180 & 0.91 & 0.78 & 1.05 & 111 & 2.6 \\
\hline & Stockport & 284,700 & & 0.84 & 0.78 & 0.61 & 0.88 & 0.83 & 95 & 0.79 & 0.66 & 0.94 & 89 & 6.4 \\
\hline & Tameside and Glossop & 250,700 & & 1.33 & 0.76 & 0.90 & 0.96 & 0.97 & 104 & 0.98 & 0.83 & 1.17 & 104 & 5.9 \\
\hline & Trafford & 217,100 & & 1.13 & 0.61 & 0.98 & 1.35 & 0.55 & 60 & 0.92 & 0.76 & 1.11 & 99 & 11.2 \\
\hline & Warrington & 199,100 & 0.73 & 0.74 & 0.60 & 1.05 & 0.61 & 0.46 & 50 & 0.70 & 0.57 & 0.86 & 76 & 3.5 \\
\hline & Western Cheshire & 234,300 & 0.89 & 0.87 & 0.54 & 0.89 & 1.23 & 1.13 & 137 & 0.93 & 0.79 & 1.08 & 110 & 3.1 \\
\hline & Wirral & 308,800 & 0.78 & 0.76 & 0.79 & 0.83 & 0.90 & 1.05 & 123 & 0.85 & 0.74 & 0.98 & 99 & 2.8 \\
\hline
\end{tabular}


Table 1.2. Continued

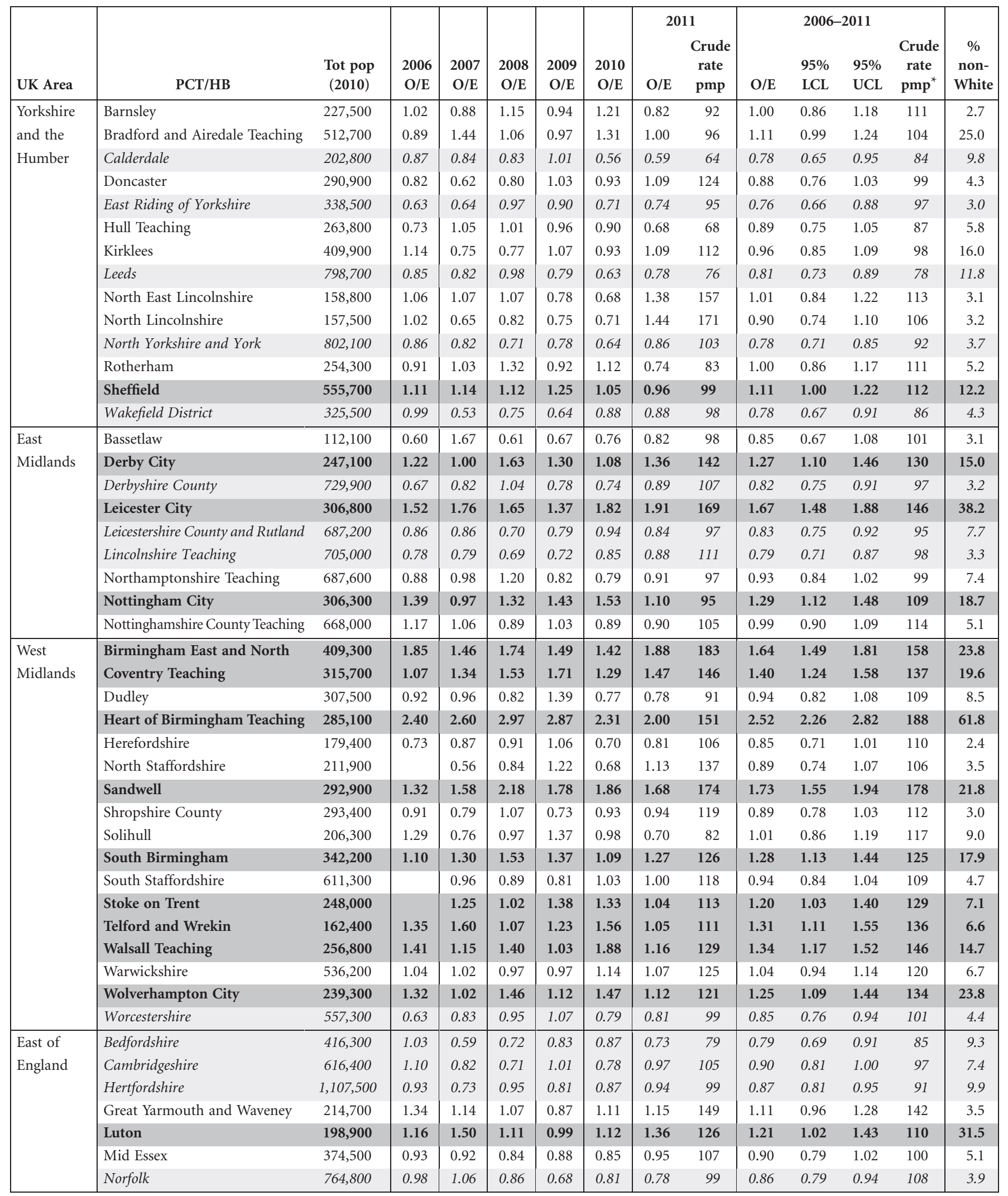


Table 1.2. Continued

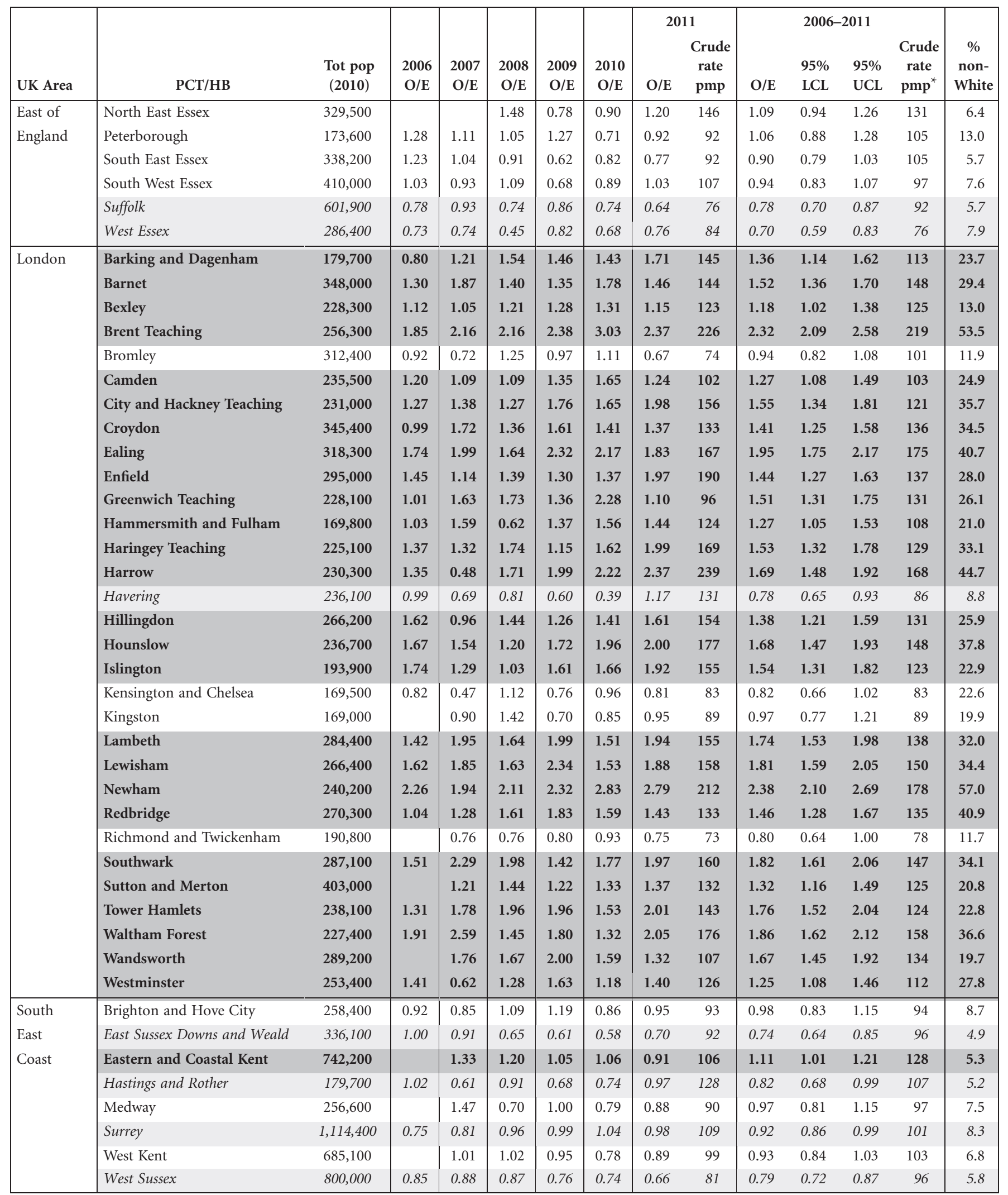


Table 1.2. Continued

\begin{tabular}{|c|c|c|c|c|c|c|c|c|c|c|c|c|c|c|}
\hline UK Area & $\mathrm{PCT} / \mathrm{HB}$ & $\begin{array}{c}\text { Tot pop } \\
(2010)\end{array}$ & $\begin{array}{c}2006 \\
\mathrm{O} / \mathrm{E}\end{array}$ & $\begin{array}{c}2007 \\
\mathrm{O} / \mathrm{E}\end{array}$ & $\begin{array}{l}2008 \\
\mathrm{O} / \mathrm{E}\end{array}$ & $\begin{array}{c}2009 \\
\mathrm{O} / \mathrm{E}\end{array}$ & $\begin{array}{l}2010 \\
\mathrm{O} / \mathrm{E}\end{array}$ & $\mathrm{O} / \mathrm{E}$ & $\begin{array}{l}1 \\
\text { Crude } \\
\text { rate } \\
\text { pmp }\end{array}$ & $\mathrm{O} / \mathrm{E}$ & $\begin{array}{l}95 \% \\
\text { LCL }\end{array}$ & $\begin{array}{l}95 \% \\
\text { UCL }\end{array}$ & $\begin{array}{c}\text { Crude } \\
\text { rate } \\
\text { pmp }^{*}\end{array}$ & $\begin{array}{c}\% \\
\text { non- } \\
\text { White }\end{array}$ \\
\hline \multirow{9}{*}{$\begin{array}{l}\text { South } \\
\text { Central }\end{array}$} & Berkshire East & 406,500 & 1.07 & 1.34 & 1.21 & 1.32 & 1.28 & 1.29 & 125 & 1.25 & 1.12 & 1.40 & 120 & 18.9 \\
\hline & Berkshire West & 471,500 & 0.94 & 0.90 & 1.12 & 0.87 & 0.76 & 1.06 & 106 & 0.94 & 0.83 & 1.06 & 93 & 10.1 \\
\hline & Buckinghamshire & 512,100 & 0.71 & 0.75 & 0.82 & 0.94 & 0.76 & 0.83 & 92 & 0.80 & 0.71 & 0.90 & 88 & 10.4 \\
\hline & Hampshire & $1,297,200$ & 0.90 & 0.78 & 0.82 & 0.82 & 0.78 & 0.73 & 86 & 0.80 & 0.75 & 0.86 & 93 & 4.2 \\
\hline & Isle of Wight National Health Service & 140,200 & 0.43 & 0.22 & 0.32 & 0.16 & 0.60 & 0.79 & 107 & 0.42 & 0.31 & 0.56 & 56 & 3.6 \\
\hline & Milton Keynes & 247,000 & 0.69 & 1.17 & 0.95 & 0.95 & 1.06 & 0.99 & 93 & 0.97 & 0.82 & 1.15 & 90 & 12.7 \\
\hline & Oxfordshire & 624,200 & 0.75 & 0.73 & 0.68 & 1.04 & 0.94 & 1.05 & 111 & 0.86 & 0.78 & 0.96 & 90 & 8.1 \\
\hline & Portsmouth City Teaching & 207,200 & 0.78 & 0.78 & 0.83 & 0.72 & 0.58 & 1.27 & 121 & 0.83 & 0.68 & 1.01 & 77 & 8.0 \\
\hline & Southampton City & 239,800 & 0.69 & 0.87 & 1.19 & 0.64 & 1.21 & 1.12 & 104 & 0.95 & 0.80 & 1.13 & 87 & 11.4 \\
\hline \multirow{14}{*}{$\begin{array}{l}\text { South } \\
\text { West }\end{array}$} & Bath and North East Somerset & 179,800 & 0.86 & 0.98 & 0.72 & 1.36 & 0.67 & 0.60 & 67 & 0.87 & 0.71 & 1.05 & 95 & 5.8 \\
\hline & Bournemouth and Poole Teaching & 310,800 & 0.67 & 0.67 & 0.87 & 0.58 & 0.56 & 0.74 & 87 & 0.68 & 0.58 & 0.80 & 79 & 5.0 \\
\hline & Bristol & 441,100 & 1.40 & 1.03 & 1.50 & 1.19 & 1.42 & 1.35 & 125 & 1.31 & 1.18 & 1.47 & 119 & 11.6 \\
\hline & Cornwall and Isles of Scilly & 537,900 & 1.06 & 0.95 & 0.90 & 1.03 & 0.88 & 0.80 & 102 & 0.94 & 0.85 & 1.04 & 119 & 2.8 \\
\hline & Devon & 749,700 & 0.92 & 1.07 & 1.15 & 1.01 & 0.94 & 0.86 & 112 & 0.99 & 0.91 & 1.08 & 127 & 3.3 \\
\hline & Dorset & 404,900 & 0.55 & 0.69 & 0.90 & 0.69 & 0.61 & 0.65 & 91 & 0.68 & 0.60 & 0.77 & 94 & 3.5 \\
\hline & Gloucestershire & 593,600 & 1.01 & 0.88 & 0.66 & 1.12 & 0.87 & 0.89 & 104 & 0.90 & 0.82 & 1.00 & 105 & 4.7 \\
\hline & North Somerset & 212,100 & 0.85 & 0.78 & 1.13 & 0.88 & 0.94 & 0.80 & 99 & 0.90 & 0.76 & 1.06 & 109 & 3.6 \\
\hline & Plymouth Teaching & 258,900 & 1.80 & 1.71 & 1.02 & 1.16 & 1.22 & 1.07 & 112 & 1.33 & 1.16 & 1.52 & 136 & 4.4 \\
\hline & Somerset & 525,500 & 0.76 & 0.69 & 0.75 & 1.07 & 1.06 & 0.81 & 103 & 0.86 & 0.77 & 0.95 & 107 & 3.2 \\
\hline & South Gloucestershire & 264,900 & 1.00 & 0.84 & 0.98 & 0.65 & 1.13 & 0.62 & 68 & 0.87 & 0.74 & 1.02 & 94 & 5.0 \\
\hline & Swindon & 206,900 & 0.76 & 0.57 & 1.10 & 1.09 & 1.06 & 1.18 & 121 & 0.96 & 0.80 & 1.15 & 97 & 7.1 \\
\hline & Torbay & 134,400 & 0.80 & 0.87 & 1.56 & 0.68 & 1.45 & 0.84 & 112 & 1.03 & 0.85 & 1.24 & 134 & 3.1 \\
\hline & Wiltshire & 459,800 & 0.71 & 0.63 & 0.85 & 0.75 & 0.82 & 0.65 & 76 & 0.73 & 0.65 & 0.83 & 85 & 3.4 \\
\hline \multirow[t]{7}{*}{ Wales } & Betsi Cadwaladr University & 678,500 & 1.11 & 1.11 & 0.95 & 0.87 & 0.92 & 0.87 & 106 & 0.97 & 0.89 & 1.06 & 117 & 1.0 \\
\hline & Powys Teaching & 131,100 & 0.63 & 0.98 & 0.93 & 1.02 & 0.70 & 1.24 & 168 & 0.92 & 0.75 & 1.12 & 122 & 0.9 \\
\hline & Hywel Dda & 374,800 & 0.91 & 1.10 & 1.25 & 0.78 & 1.17 & 1.12 & 141 & 1.05 & 0.94 & 1.18 & 132 & 1.0 \\
\hline & Abertawe Bro Morgannwg Univ. & 504,800 & 1.40 & 1.50 & 1.20 & 1.55 & 1.48 & 1.11 & 129 & 1.37 & 1.25 & 1.50 & 157 & 1.6 \\
\hline & Cwm Taf & 290,600 & 1.68 & 1.61 & 1.07 & 1.31 & 0.96 & 1.43 & 158 & 1.34 & 1.19 & 1.52 & 147 & 1.1 \\
\hline & Aneurin Bevan & 561,300 & 1.10 & 1.35 & 0.95 & 0.96 & 1.32 & 1.17 & 134 & 1.14 & 1.04 & 1.25 & 129 & 1.9 \\
\hline & Cardiff and Vale University & 466,100 & 1.40 & 1.45 & 1.01 & 1.15 & 1.38 & 0.99 & 99 & 1.23 & 1.11 & 1.37 & 121 & 6.7 \\
\hline \multirow[t]{14}{*}{ Scotland } & Ayrshire \& Arran & 366,900 & 1.39 & 0.85 & 0.83 & 0.89 & 1.09 & 0.79 & 95 & 0.97 & 0.86 & 1.10 & 116 & 0.7 \\
\hline & Borders & 113,000 & 0.91 & 1.21 & 1.07 & 0.98 & 1.07 & 0.56 & 71 & 0.97 & 0.78 & 1.20 & 121 & 0.6 \\
\hline & Dumfries and Galloway & 148,100 & 1.13 & 0.83 & 1.14 & 1.07 & 0.57 & 0.56 & 74 & 0.89 & 0.73 & 1.07 & 116 & 0.7 \\
\hline & Fife & 364,800 & 1.02 & 1.00 & 0.95 & 1.18 & 1.19 & 1.13 & 129 & 1.08 & 0.96 & 1.22 & 122 & 1.3 \\
\hline & Forth Valley & 293,100 & 1.02 & 1.35 & 0.78 & 0.99 & 1.01 & 0.80 & 89 & 0.99 & 0.86 & 1.14 & 109 & 1.1 \\
\hline & Grampian & 550,500 & 0.82 & 0.86 & 0.88 & 0.90 & 0.85 & 0.81 & 91 & 0.85 & 0.76 & 0.96 & 94 & 1.6 \\
\hline & Greater Glasgow \& Clyde & $1,204,100$ & 1.11 & 1.09 & 0.94 & 1.00 & 0.88 & 1.03 & 109 & 1.01 & 0.94 & 1.08 & 105 & 3.4 \\
\hline & Highland & 310,700 & 0.86 & 0.87 & 0.84 & 0.75 & 0.64 & 0.49 & 61 & 0.74 & 0.64 & 0.86 & 91 & 0.8 \\
\hline & Lanarkshire & 562,700 & 0.92 & 0.81 & 0.74 & 0.85 & 0.99 & 0.82 & 89 & 0.85 & 0.76 & 0.95 & 92 & 1.2 \\
\hline & Lothian & 837,000 & 1.04 & 0.88 & 0.98 & 0.82 & 0.63 & 0.69 & 72 & 0.84 & 0.77 & 0.92 & 86 & 2.8 \\
\hline & Orkney & 19,800 & 0.82 & 0.42 & 1.66 & 1.23 & 0.42 & 0.00 & 0 & 0.76 & 0.42 & 1.37 & 93 & 0.4 \\
\hline & Shetland & 22,500 & 0.00 & 1.58 & 0.00 & 0.39 & 0.40 & 0.78 & 89 & 0.52 & 0.26 & 1.05 & 59 & 1.1 \\
\hline & Tayside & 402,400 & 1.06 & 1.24 & 1.17 & 1.28 & 1.01 & 1.13 & 134 & 1.15 & 1.03 & 1.28 & 135 & 1.9 \\
\hline & Western Isles & 26,500 & 0.88 & 1.78 & 0.30 & 0.88 & 1.49 & 0.00 & 0 & 0.88 & 0.56 & 1.40 & 113 & 0.6 \\
\hline \multirow[t]{5}{*}{$\mathrm{N}$ Ireland } & Belfast & 335,700 & 1.58 & 1.29 & 1.02 & 0.80 & 1.28 & 1.12 & 113 & 1.18 & 1.04 & 1.34 & 118 & 1.1 \\
\hline & Northern & 458,600 & 1.27 & 1.39 & 1.13 & 0.81 & 1.17 & 1.22 & 126 & 1.17 & 1.05 & 1.30 & 119 & 0.6 \\
\hline & Southern & 357,700 & 0.66 & 0.60 & 0.96 & 0.78 & 1.07 & 1.31 & 123 & 0.90 & 0.77 & 1.04 & 83 & 0.4 \\
\hline & South Eastern & 347,100 & 1.02 & 0.89 & 0.86 & 0.69 & 0.71 & 0.91 & 95 & 0.85 & 0.73 & 0.98 & 88 & 0.7 \\
\hline & Western & 299,900 & 1.26 & 1.03 & 0.85 & 1.20 & 0.83 & 0.98 & 93 & 1.03 & 0.88 & 1.19 & 97 & 0.5 \\
\hline
\end{tabular}




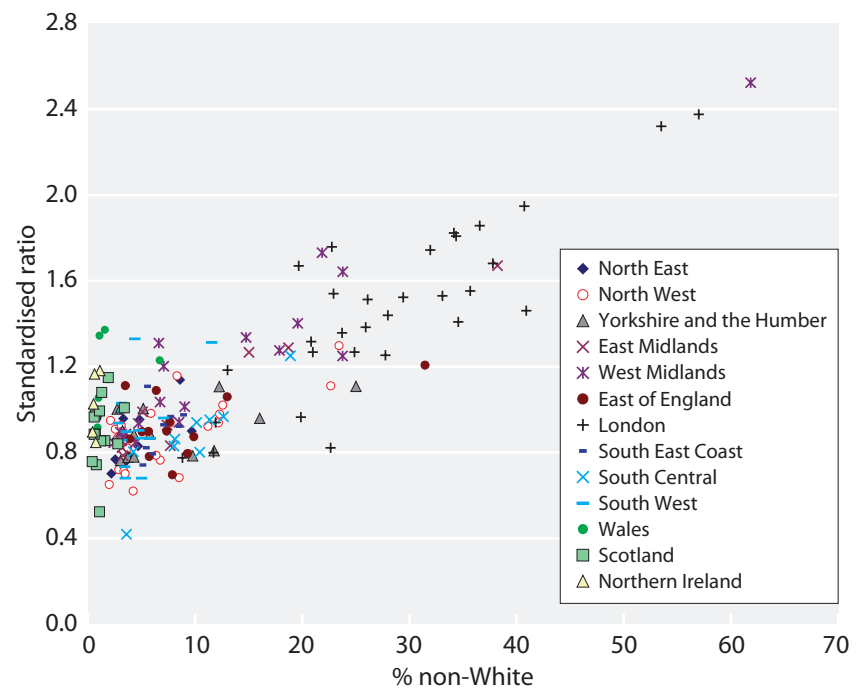

Fig. 1.2. Age/gender standardised incidence ratio (2006-2011) by percentage non-White

results are not shown for any centre with fewer than 10 incident patients in the year. Individual EDTA codes for primary diagnoses were grouped into eight categories, the details are given in appendix H: Ethnicity and ERA-EDTA Coding (www.renalreg.com). EDTA code 10, 'Glomerulonephritis biopsy unproven', was now put in the 'Glomerulonephritis' group rather than into the 'Uncertain' aetiology group as was done in previous year's reports.

Most centres electronically upload ethnicity coding to their renal information technology (IT) system from the hospital Patient Administration System (PAS). Ethnicity coding in these PAS systems is based on self-reported ethnicity. For the remaining centres, ethnicity coding is performed by clinical staff and recorded directly into the renal IT system (using a variety of coding systems). For all these analyses, data on ethnic origin were grouped into Whites, South Asians, Blacks, Chinese and Others. The details of regrouping of the PAS codes into the above ethnic categories are provided in appendix H: Ethnicity and ERA-EDTA Coding (www.renalreg.com). Chi-squared, Fisher's exact, ANOVA and Kruskal Wallis tests were used as appropriate to test for significant differences.

Estimated glomerular filtration rate (eGFR) at the start of RRT was studied amongst patients with eGFR data within 14 days before the start of RRT. The eGFR was calculated using the abbreviated 4 variable MDRD study equation [2]. For the purpose of the eGFR calculation, patients who had missing ethnicity but a valid serum creatinine measurement were classed as Whites. The eGFR values were log transformed in order to normalise the data. Patients with an eGFR $>20 \mathrm{ml} / \mathrm{min} / 1.73 \mathrm{~m}^{2}$ were excluded from the eGFR analyses due to concerns about possible data extraction errors.

\section{Results}

Age

Overall, incidence rates have levelled off in the last five years (figure 1.3).
Figure 1.4 shows RRT incidence rates for 2011 by age group and gender. For both men and women, the peak rate was in the 75-79 age group.

In 2011, the median age of patients starting renal replacement therapy was 64.9 years (table 1.4) and this had changed little over the previous six years (data not shown). The median age of non-White patients was considerably lower at 58.4 years. This reflects the younger age distribution of ethnic minority populations in general compared with the White population $(5.1 \%$ of ethnic minorities were over 65 years old compared to $16.9 \%$ of Whites) [3] and the higher rates of diabetes in South Asian and Black populations.

Figure 1.5 shows that the 55-64 and 65-74 age groups contained the most patients starting on peritoneal dialysis whereas the 65-74 age group contained the most patients starting on haemodialysis closely followed by the 75-84 age group. The figure also gives the numbers for 2010 showing that there was an increase in 2011 in the numbers starting $\mathrm{PD}$, most notably in the $65-74$ age group.

There were large differences between centres in the median age of incident patients (figure 1.6). This reflects differences in the age and ethnic structure of the catchment populations and also chance fluctuations, particularly in small centres. The median age of patients treated at transplant centres was 63.8 years (IQR 49.5, 74.3 ) and at non-transplanting centres 66.2 years (IQR 52.4, 76.0) $(\mathrm{p}<0.0001)$.

Whilst the median age of patients had risen only slightly over the last 10 years the percentage of patients aged over 75 years rose from $22.3 \%$ to $25.2 \%$.

Averaged over 2006-2011, crude incidence rates in the over 75 years age group varied from 0 per million age related population (pmarp) (Shetland) to 989 pmarp (Heart of Birmingham).

Excluding four areas which had much higher or lower rates than the rest there was 6-fold variation (104 pmarp to 637 pmarp). The wide range of treatment rates suggests there was geographical variation in the prevalence of comorbid and predisposing renal conditions within the UK as well as uncertainty within the renal community about the suitability of older patients for dialysis. The 6 -fold variation seen in the over $75 \mathrm{~s}$ was much greater than the 2.4 -fold variation $(73 \mathrm{pmp}$ to $178 \mathrm{pmp}$ ) seen in the overall analysis although a proportion of this difference is likely to be due to the smaller numbers included in the over $75 \mathrm{~s}$ analysis.

The median age of new patients with diabetes was similar to the overall median and has not varied greatly over the last 5 years. 
Table 1.3. Number of patients starting RRT by renal centre 2006-2011

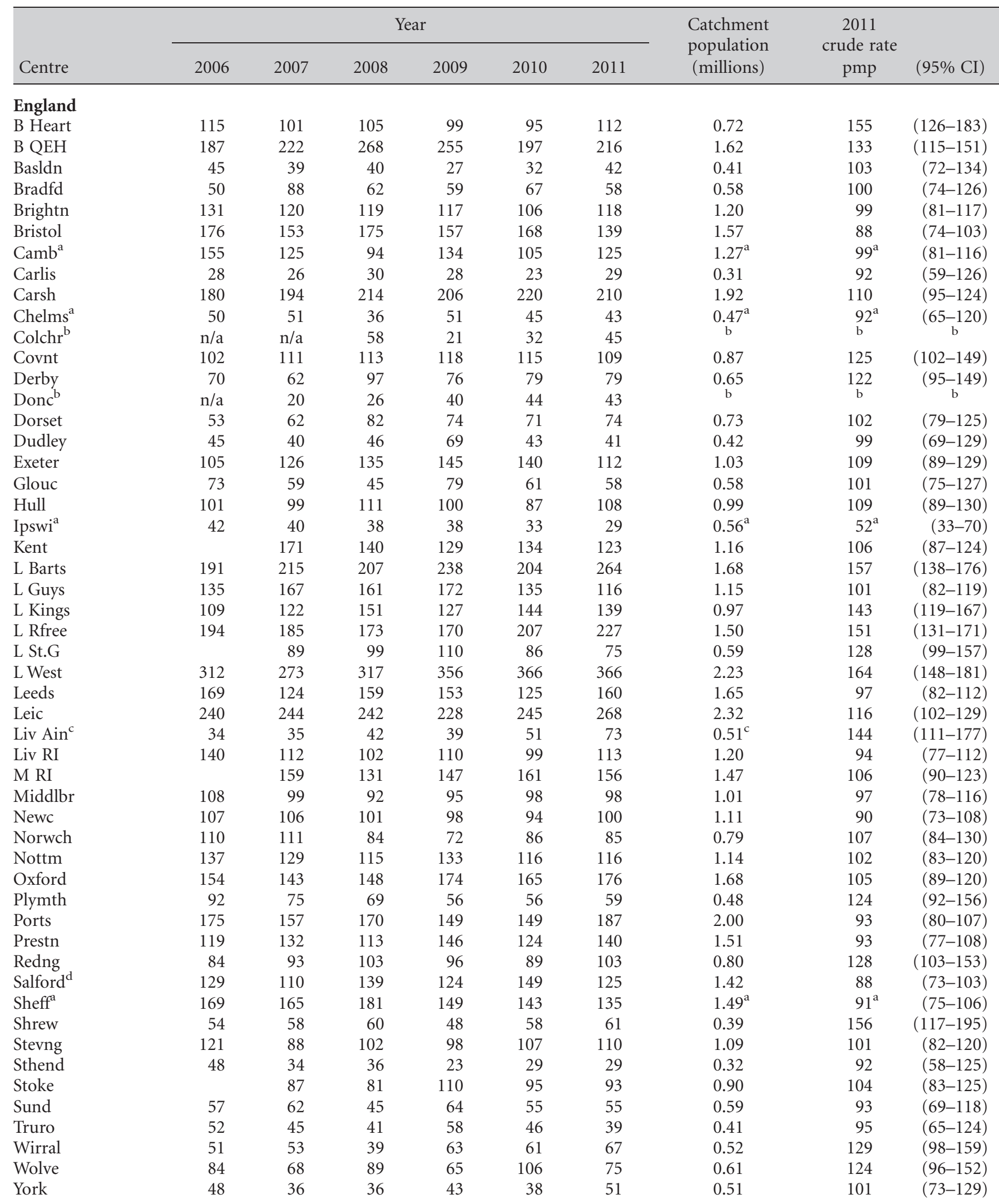


Table 1.3. Continued

\begin{tabular}{|c|c|c|c|c|c|c|c|c|c|}
\hline \multirow[b]{2}{*}{ Centre } & \multicolumn{6}{|c|}{ Year } & \multirow{2}{*}{$\begin{array}{l}\text { Catchment } \\
\text { population } \\
\text { (millions) }\end{array}$} & \multirow{2}{*}{$\begin{array}{c}2011 \\
\text { crude rate } \\
\text { pmp }\end{array}$} & \multirow[b]{2}{*}{$(95 \% \mathrm{CI})$} \\
\hline & 2006 & 2007 & 2008 & 2009 & 2010 & 2011 & & & \\
\hline \multicolumn{10}{|l|}{ N Ireland } \\
\hline Antrim & 33 & 37 & 41 & 21 & 41 & 29 & 0.30 & 97 & $(61-132)$ \\
\hline Belfast & 121 & 90 & 70 & 59 & 72 & 68 & 0.55 & 123 & $(94-152)$ \\
\hline Newry & 13 & 15 & 21 & 19 & 21 & 38 & 0.28 & 134 & $(92-177)$ \\
\hline Ulster & 8 & 17 & 14 & 13 & 20 & 34 & 0.30 & 113 & $(75-151)$ \\
\hline West $\mathrm{NI}^{\mathrm{e}}$ & 33 & 29 & 31 & 37 & 26 & 34 & 0.35 & 96 & $(64-129)$ \\
\hline \multicolumn{10}{|l|}{ Scotland ${ }^{\mathrm{f}}$} \\
\hline Abrdn & 53 & 56 & 56 & 55 & 51 & 49 & 0.60 & 82 & $(59-105)$ \\
\hline Airdrie & 55 & 48 & 39 & 48 & 56 & 48 & 0.56 & 85 & $(61-109)$ \\
\hline D \& Gall & 20 & 17 & 19 & 17 & 10 & 10 & 0.15 & 68 & $(26-109)$ \\
\hline Dundee & 51 & 62 & 64 & 69 & 50 & 57 & 0.41 & 140 & $(104-177)$ \\
\hline Dunfn & 37 & 37 & 30 & 33 & 45 & 43 & 0.37 & 117 & $(82-152)$ \\
\hline Edinb & 106 & 95 & 103 & 98 & 68 & 72 & 0.96 & 75 & $(58-92)$ \\
\hline Glasgw & 186 & 187 & 159 & 174 & 154 & 171 & 1.51 & 114 & $(97-131)$ \\
\hline Inverns & 26 & 26 & 25 & 21 & 27 & 12 & 0.34 & 35 & $(15-56)$ \\
\hline Klmarnk & 57 & 36 & 33 & 39 & 43 & 33 & 0.37 & 90 & $(59-121)$ \\
\hline \multicolumn{10}{|l|}{ Wales } \\
\hline Bangor & 42 & 36 & 41 & 30 & 26 & 20 & 0.25 & 80 & $(45-115)$ \\
\hline Cardff & 203 & 220 & 150 & 177 & 186 & 182 & 1.45 & 126 & $(107-144)$ \\
\hline Clwyd $^{\mathrm{g}}$ & 18 & 21 & 15 & 18 & 15 & $21^{\mathrm{g}}$ & 0.20 & 105 & $(60-150)$ \\
\hline Swanse & 116 & 127 & 125 & 116 & 137 & 114 & 0.80 & 143 & $(116-169)$ \\
\hline \multirow[t]{2}{*}{ Wrexm } & 26 & 27 & 21 & 20 & 25 & 26 & 0.30 & 87 & $(53-120)$ \\
\hline & & & & & \multicolumn{5}{|c|}{$\begin{array}{l}\text { \% change since } \\
\qquad 2007^{\mathrm{i}}\end{array}$} \\
\hline England & $5,131^{\mathrm{h}}$ & 5,485 & 5,662 & 5,736 & 5,584 & 5,774 & 5.3 & & \\
\hline N Ireland & 208 & 188 & 177 & 149 & 180 & 203 & 8.0 & & \\
\hline Scotland & 591 & 564 & 528 & 554 & 504 & 495 & -12.2 & & \\
\hline Wales & 405 & 431 & 352 & 361 & 389 & 363 & -15.8 & & \\
\hline UK & $6,335^{\mathrm{h}}$ & 6,668 & 6,719 & 6,800 & 6,657 & 6,835 & 2.5 & & \\
\hline
\end{tabular}

Blank cells - no data returned to the registry for that year

$\mathrm{n} / \mathrm{a}$ - renal centre not yet operational

pmp - per million population

${ }^{a}$ Some reduction required to the population and increase to the rate after the opening of Colchester renal centre and the expansion of Doncaster renal centre

${ }^{\mathrm{b}}$ Colchester renal centre was opened in 2007, Doncaster was still expanding and so catchment populations could not be calculated (2007 data was used for catchment population estimations)

${ }^{c}$ Population changed from 0.29 to 0.51 at the centre's request. Therefore the populations given for nearby centres are probably somewhat too high

${ }^{\mathrm{d}}$ Salford previously named M Hope

${ }^{\mathrm{e}}$ West NI is the amalgamation of Derry and Tyrone

${ }^{\mathrm{f}}$ Populations for Scottish centres based on mid-2011 populations of Health Boards (from the General Register Office for Scotland) and an approximate mapping of renal centres to HBs supplied by the Scottish Renal Registry

${ }^{\mathrm{g}}$ Clywd had 21 incident patients in 2011 but only 7 of these were included in the data extract. The extra 14 patients have been included in tables 1.1, 1.2 and 1.3 but not in the remainder of this chapter. Clywd are therefore not shown in any of the subsequent tables or figures as there were fewer than 10 patients with full data

${ }^{\mathrm{h}}$ Does not include Kent, L St.G, M RI or Stoke as they were not reporting to the registry for 2006

${ }^{\mathrm{i}}$ Change shown from 2007 not 2006 as not all centres included in 2006 data 


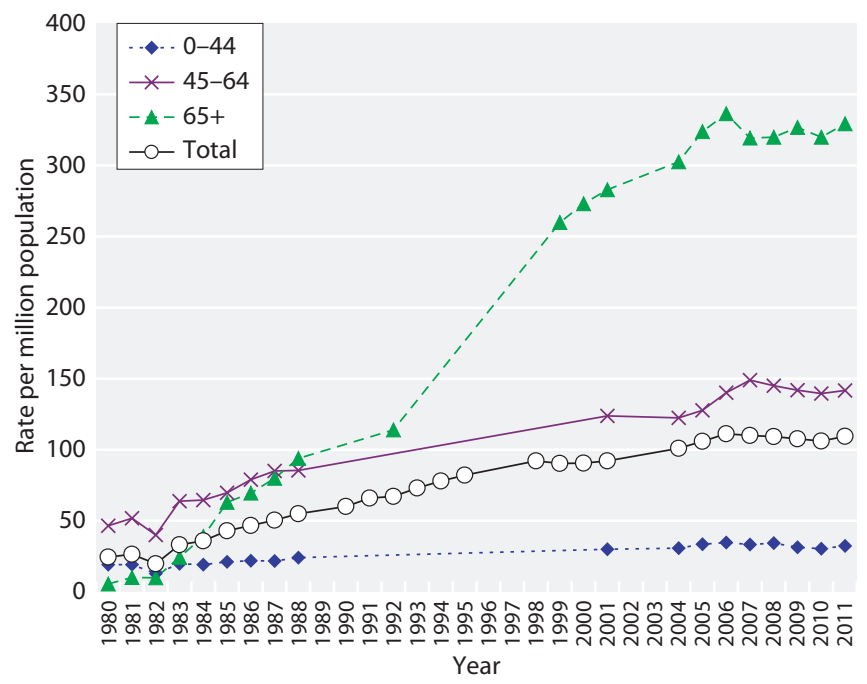

Fig. 1.3. RRT incidence rates between 1980 and 2011

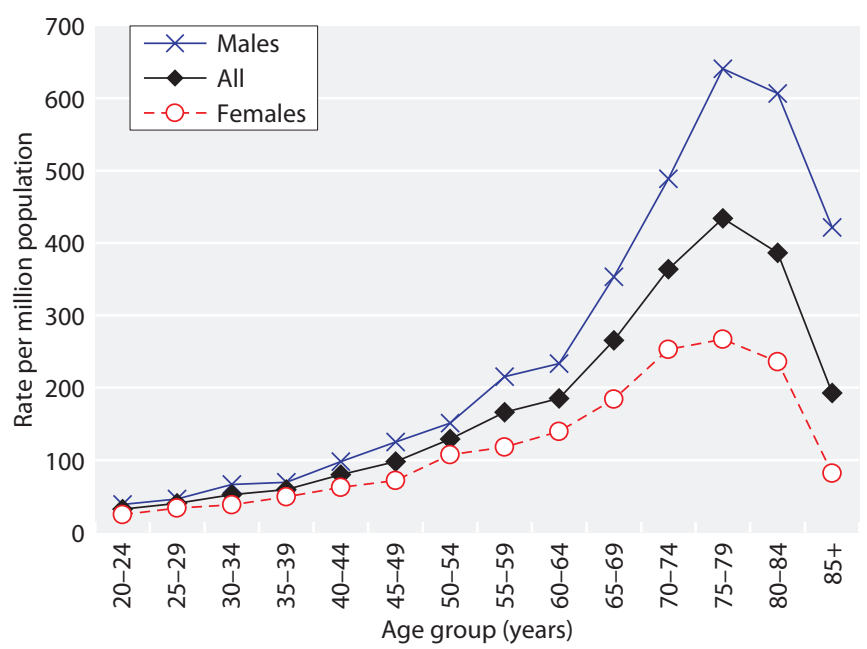

Fig. 1.4. RRT incidence rates in 2011 by age and gender
Table 1.4. Median and inter-quartile range of the age of patients starting renal replacement therapy in 2011 by country

\begin{tabular}{lcc}
\hline Country & Median & IQR \\
\hline England & 64.9 & $(50.7-75.0)$ \\
N Ireland & 64.7 & $(49.9-74.0)$ \\
Scotland & 64.8 & $(53.1-74.4)$ \\
Wales & 66.4 & $(52.9-76.3)$ \\
UK & $\mathbf{6 4 . 9}$ & $(\mathbf{5 0 . 9 - 7 5 . 1 )}$ \\
\hline
\end{tabular}

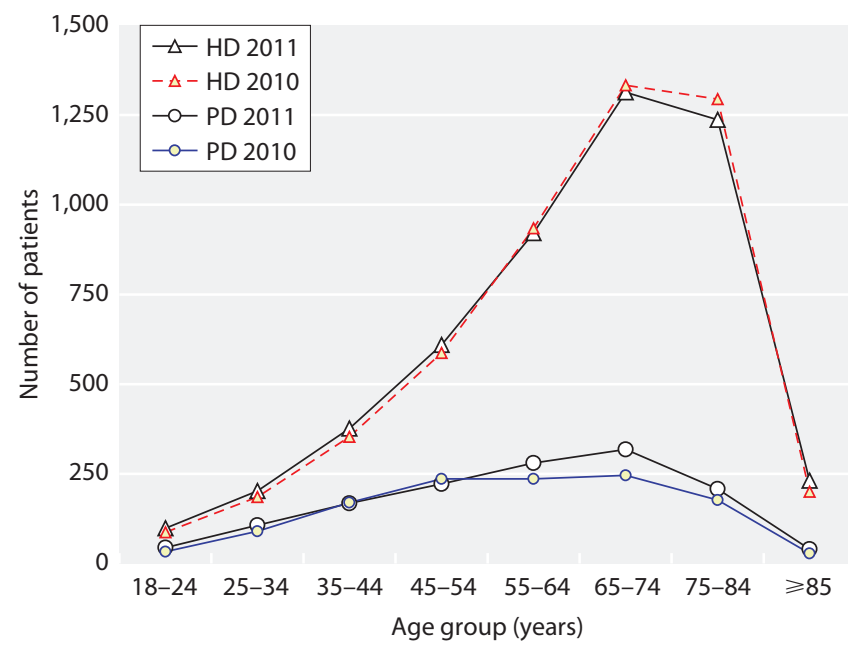

Fig. 1.5. Number of incident RRT patients in 2011 (and 2010), by age group and initial dialysis modality

\section{Gender}

As in previous years, more men than women started RRT (63.0\% male). The male percentage was above 50 for all age groups and increased with increasing age group after age 45 (figure 1.7). The male to female

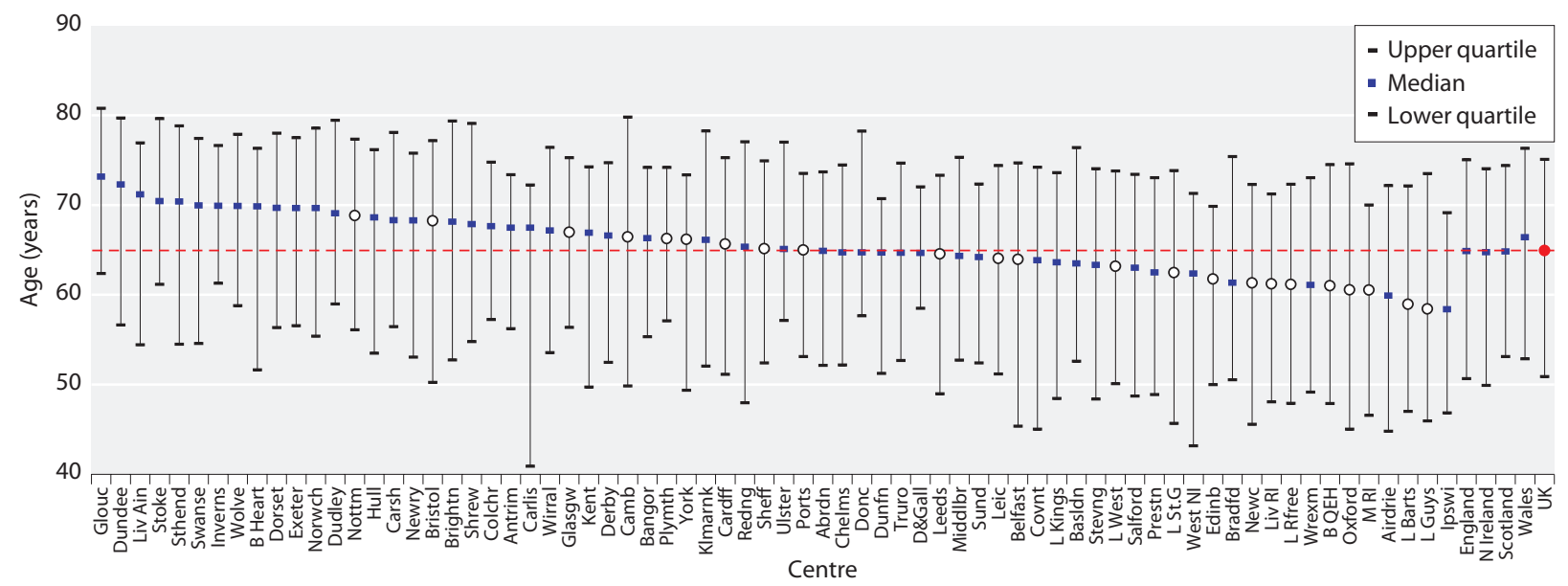

Fig. 1.6. Median age of incident RRT patients by centre in 2011 White points indicate transplant centres 


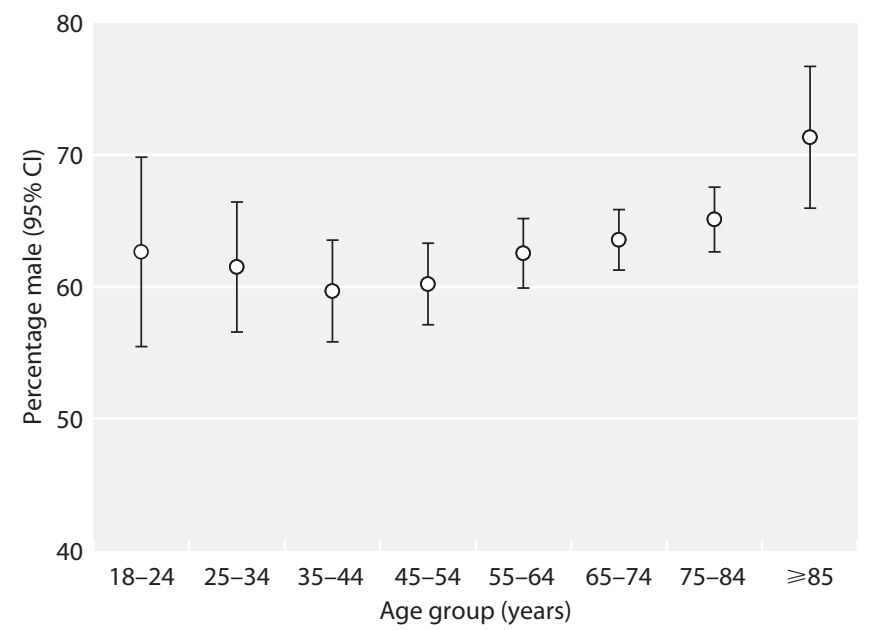

Fig. 1.7. Percentage of patients starting RRT in 2011 who were male, by age group

ratio which had been consistently stable at 1.6 since 1998 has increased over the last 2 years to 1.7.

\section{Ethnicity}

The completeness of ethnicity data was similar to that seen for 2010 incident patients. Fifty-nine centres returned ethnicity data that were $50 \%$ or more complete (table 1.5). This compared with 61 centres last year. Fiftythree of these 59 centres provided ethnicity data for $90 \%$ or more of their incident patients compared with 52 centres last year. Ethnicity completeness was low in the Scottish Renal Registry and Scotland has not been included in the table. The low completeness for some centres means that the overall breakdowns should still be interpreted with some caution. There was great variation between centres in the percentage of incident patients who were non-White ranging from zero in Carlisle, Dorset, Exeter, Truro, Newry and West NI to over 50\% in Barts, the Royal Free and London West.

\section{Primary renal diagnosis}

The distribution of primary renal disease (PRD) by centre is shown in table 1.6. Data for PRD were missing for $10.2 \%$ of patients and there remained marked differences between centres in completeness of data. Sixty centres provided data on over $90 \%$ of incident patients and 32 of these had 100\% completeness. There was only a small amount of missing data for Scotland and Wales and none for Northern Ireland, whilst England had $12.0 \%$ missing. The overall percentage missing was slightly up on 2010 (10.2\% from 9.8\%) and was similar in under and over 65 year olds $(10.0 \%$ and $10.4 \%$ respectively). Four centres had missing PRD for more than $25 \%$ of new patients and for these centres the percentages in the diagnostic categories are not shown in table 1.6.

The UKRR continues to be concerned about centres with apparently very high data completeness for PRD but also very high rates of 'uncertain' diagnoses (EDTA code 00: Chronic renal failure; aetiology uncertain). It is accepted that there will inevitably be a number of patients with uncertain aetiology and that the proportion of these

Table 1.5. Percentage of incident RRT patients (2011) in different ethnic groups by centre

\begin{tabular}{|c|c|c|c|c|c|c|c|}
\hline Centre & $\begin{array}{c}\% \text { data not } \\
\text { available }\end{array}$ & $\begin{array}{l}\mathrm{N} \text { with } \\
\text { data }\end{array}$ & \multicolumn{5}{|c|}{ Percentage in each ethnic group } \\
\hline B Heart & 0.9 & 111 & 62.2 & 4.5 & 32.4 & & 0.9 \\
\hline B QEH & 0.5 & 215 & 65.6 & 10.2 & 20.5 & 0.9 & 2.8 \\
\hline Basldn & 0.0 & 42 & 83.3 & 9.5 & 4.8 & & 2.4 \\
\hline Bristol & 5.0 & 132 & 85.6 & 7.6 & 5.3 & & 1.5 \\
\hline Camb & 0.0 & 125 & 96.8 & 2.4 & & & 0.8 \\
\hline Carlis & 0.0 & 29 & 100.0 & & & & \\
\hline Carsh & 10.5 & 188 & 72.3 & 10.6 & 13.8 & 0.5 & 2.7 \\
\hline Chelms & 9.3 & 39 & 89.7 & 5.1 & 2.6 & & 2.6 \\
\hline Colchr & 0.0 & 45 & 93.3 & 2.2 & & & 4.4 \\
\hline Dorset & 0.0 & 74 & 100.0 & & & & \\
\hline
\end{tabular}


Table 1.5. Continued

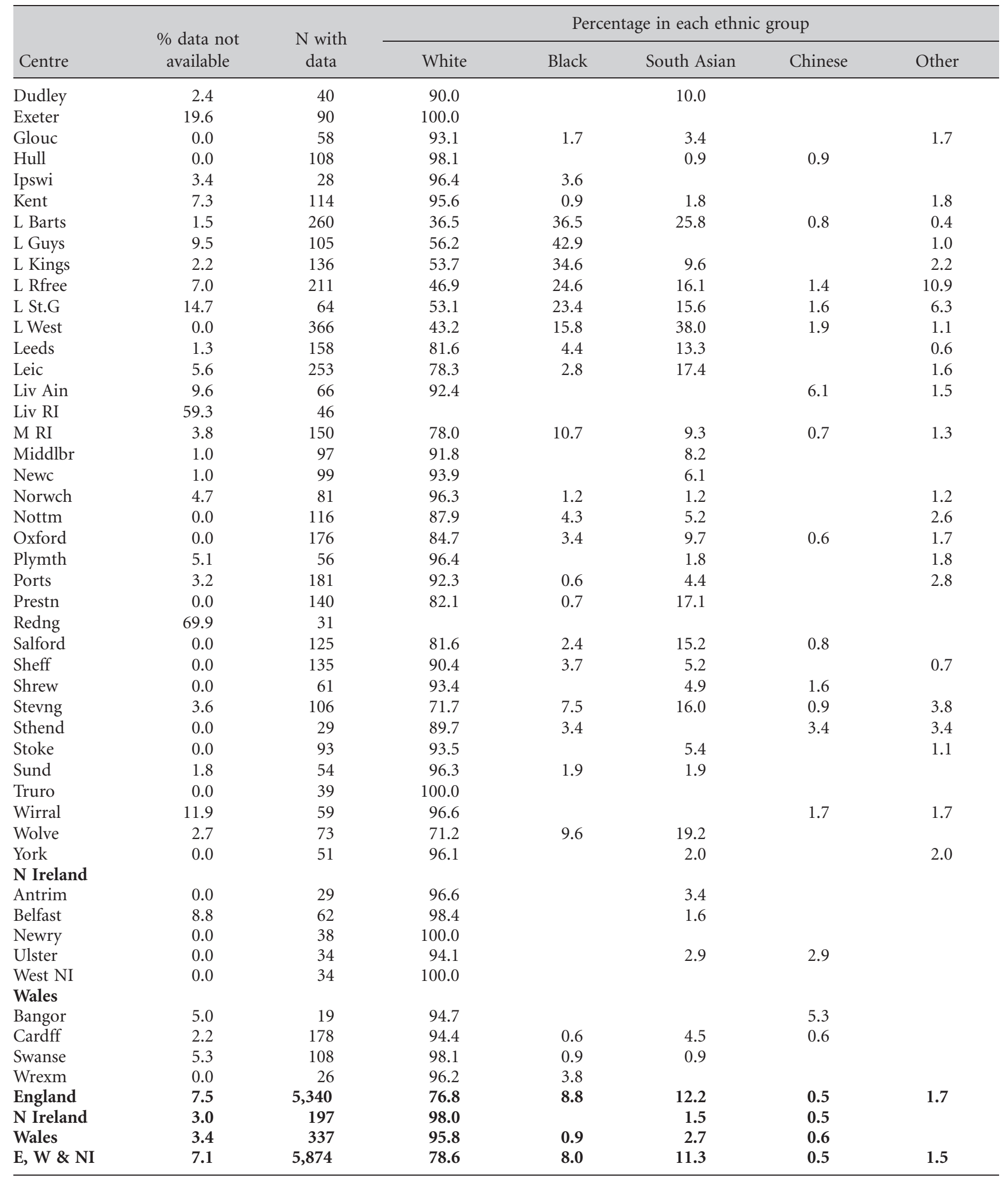

The percentage breakdown is not shown for centres with less than $50 \%$ data completeness but these centres are included in national averages 
Table 1.6. Distribution of primary renal diagnosis by centre in the 2011 incident RRT cohort

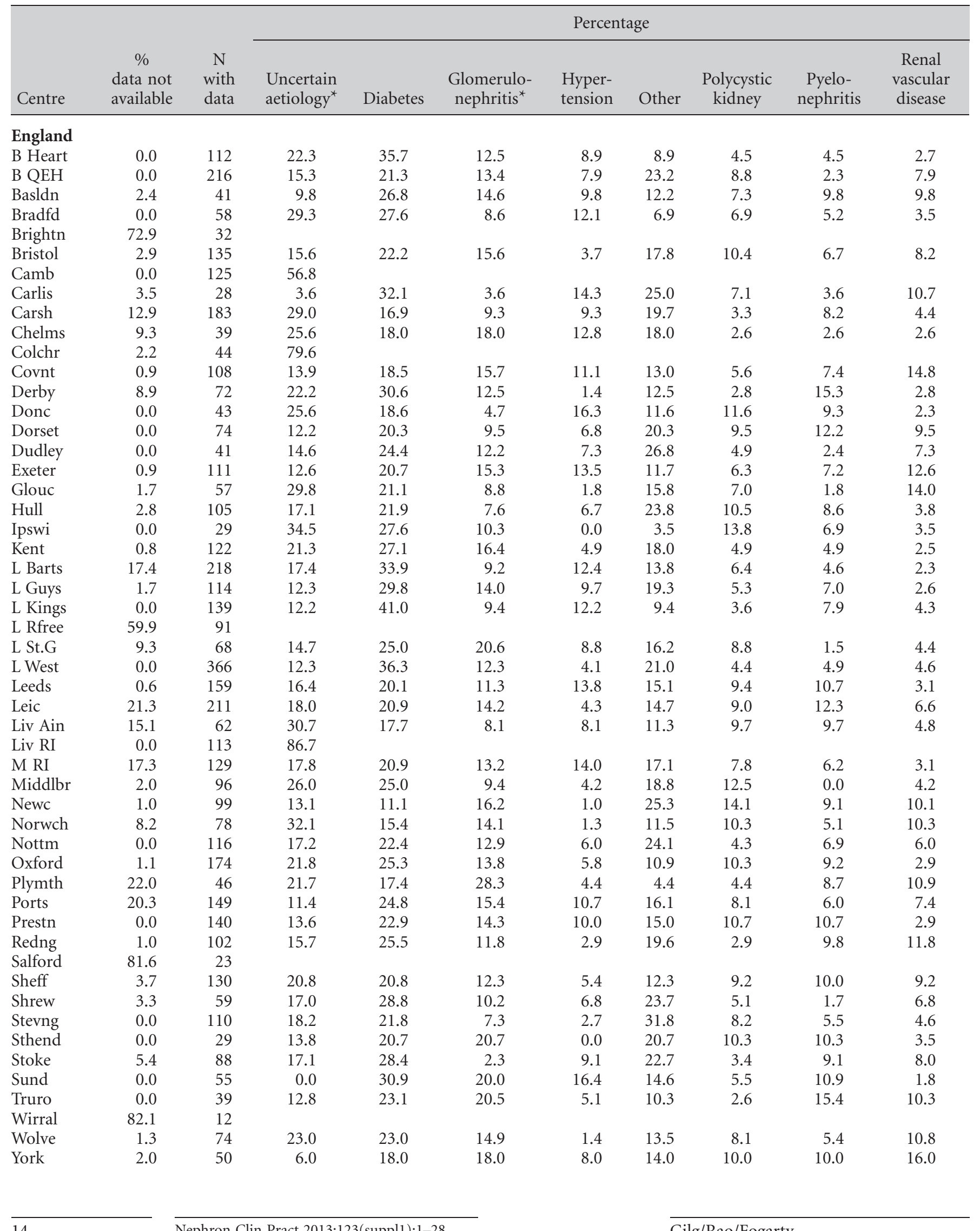


Table 1.6. Continued

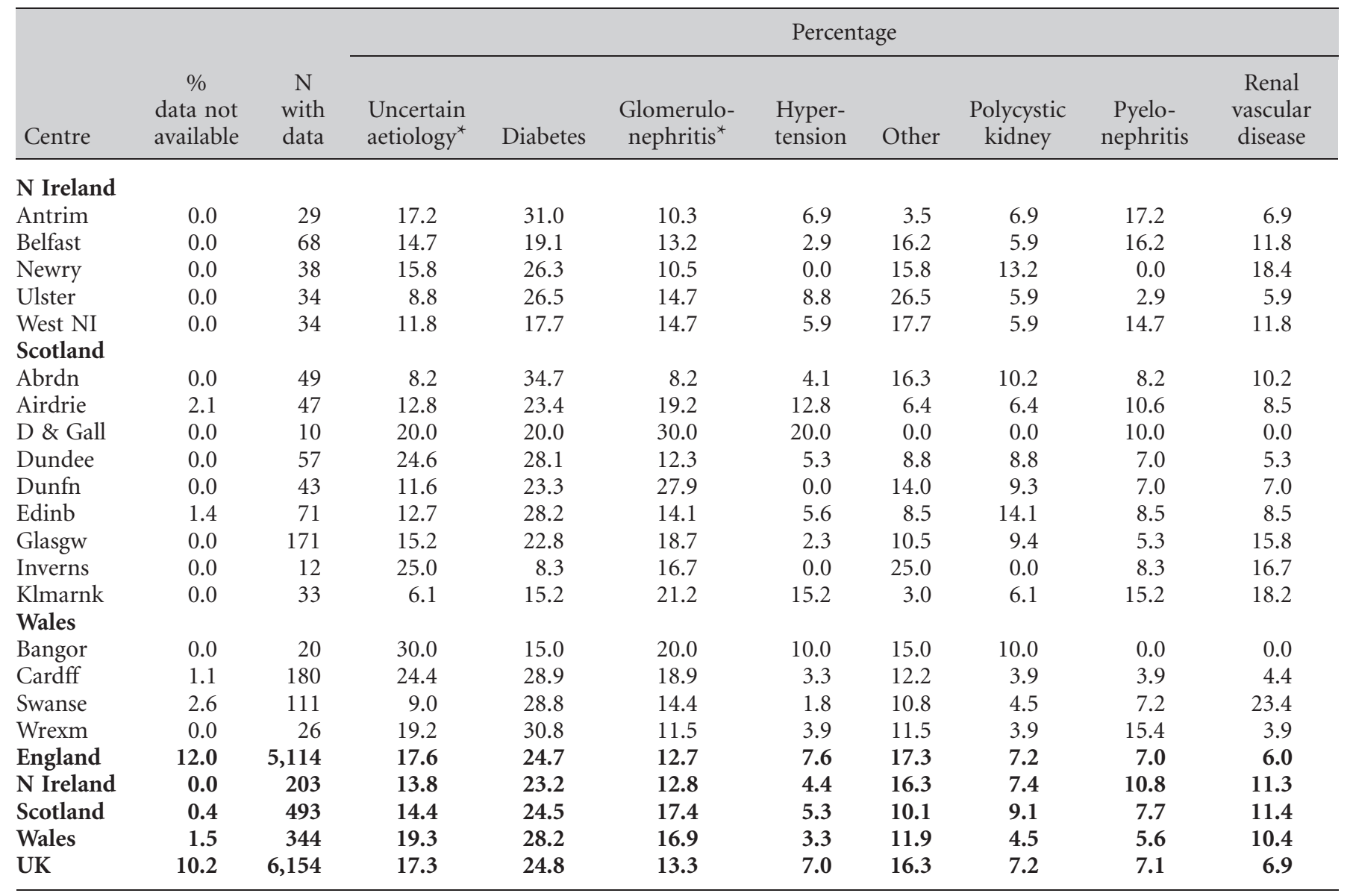

${ }^{*}$ presumed glomerulonephritis not biopsy proven has now been grouped into glomerulonephritis rather than into uncertain as in previous years

The percentage in each category has been calculated after excluding those patients with data not available

For those centres with $>25 \%$ missing primary diagnoses, the percentages in the diagnostic categories have not been calculated

For those centres judged to have high \% uncertain aetiology, the percentages in the other diagnostic categories have not been calculated and the centres have not been included in the country and UK averages

patients will vary between clinicians and centres as the definitions of e.g. renal vascular disease and hypertensive renal disease remain relatively subjective. There was again a lot of variability between centres but, as in previous years, a small number of centres had far higher percentages with 'uncertain' diagnosis than other centres. This year, data was not used from three centres which had diagnosis 'uncertain' for over $50 \%$ of their incident patients with non-missing data (Cambridge, Colchester, Royal Liverpool). As the numbers with the specific PRDs are likely to be falsely low in these centres, the breakdown into these categories has not been shown in table 1.6 or used in the country and UK averages. These centres have also been excluded where PRD is used to stratify analyses.
There was a lot of variability between centres in the percentages with the specific diagnoses. For example, the percentage with diabetes as PRD varied from about $10 \%$ to just over $40 \%$ of incident patients. The percentage with glomerulonephritis varied from below $5 \%$ to $30 \%$.

The overall percentage with uncertain aetiology was lower than last year (17.3 versus 19.8\%) but about two-thirds of this decrease was due to the reclassification of those with EDTA code 10 (Glomerulonephritis biopsy not proven) from uncertain into glomerulonephritis (when including this group in uncertain as last year the relevant percentage was $18.9 \%$ ).

The overall UK distribution of PRDs is shown in table 1.7. Diabetic nephropathy was the most common 
Table 1.7. Percentage distribution of primary renal diagnosis by age in the 2011 incident RRT cohort

\begin{tabular}{lccc}
\hline & \multicolumn{3}{c}{ Percentage with diagnosis } \\
\cline { 2 - 4 } Diagnosis & Age $<65$ & Age $\geqslant 65$ & All patients \\
\hline Diabetes & 27.2 & 22.4 & 24.8 \\
Glomerulonephritis & 17.4 & 9.2 & 13.3 \\
Pyelonephritis & 7.8 & 6.5 & 7.1 \\
Hypertension & 6.7 & 7.4 & 7.0 \\
Polycystic kidney & 10.6 & 3.8 & 7.2 \\
Renal vascular disease & 2.3 & 11.5 & 6.9 \\
Other $_{\text {Uncertain aetiology }}^{*}$ & 16.1 & 16.6 & 16.3 \\
\hline * Presumed $^{*}$ & 12.0 & 22.6 & 17.3 \\
\hline
\end{tabular}

${ }^{\star}$ Presumed glomerulonephritis not biopsy proven has now been grouped into glomerulonephritis rather than into uncertain as in previous years

Percentages calculated after excluding those patients with data not available

specific renal diagnosis in both the under and over 65 year age groups, accounting for $25 \%$ of all (non-missing) incident diagnoses. Glomerulonephritis and autosomal dominant polycystic kidney disease (ADPKD) made up higher proportions of the younger than the older incident cohorts ( $17 \%$ vs. $9 \%$ and $11 \%$ vs. $4 \%$ respectively), whilst patients with renal vascular disease comprised a much higher percentage of the older rather than the younger patients $(12 \%$ vs. $2 \%)$. Uncertainty about the underlying diagnosis was also much more likely in the older rather than the younger cohort (23\% vs. $12 \%)$.

For all primary renal diagnoses except ADPKD, the male to female ratio was 1.3 or greater. This gender difference may relate to factors such as smoking, hypertension, atheroma and renal vascular disease which are more common in males and may influence the rate of progression of renal failure.

Table 1.8 shows the incidence rates for each PRD per million population for the 2011 cohort. In both the 2010 and 2011 cohorts, the incidence of RRT due to diabetes as PRD was noticeably higher in Wales than in the other countries. As there were some missing data, the rates for at least some of the diagnoses will be underestimates.

First established treatment modality

The first treatment recorded, irrespective of any later change, was haemodialysis (HD) in $73.1 \%$ of patients, peritoneal dialysis (PD) in $20.3 \%$ and pre-emptive transplant in $6.6 \%$ in 2011. As seen last year, this continues the decrease in $\operatorname{HD}(76.3 \%, 74.8 \%, 73.1 \%)$ and increase in PD $(17.9 \%, 18.3 \%, 20.3 \%)$ seen respectively for 2009 , 2010 and 2011). For pre-emptive transplant the percentages were 5.9, 6.9 and 6.6 for the three years. Table F.1.3 in appendix F: Additional Data Tables for 2011 new and existing patients (www.renalreg.com) gives the treatment breakdown at start of RRT by centre.

Many patients undergo a brief period of HD before switches to other modalities are, or can be, considered. Therefore, the established modality at 90 days is more representative of the elective first modality and this modality was used for the remainder of this section. For these analyses, the incident cohort from 1st October 2010 to 30th September 2011 was used so that follow up to 90 days was possible for all patients. By 90 days, 5.5\% of incident patients had died and a further $0.3 \%$ had stopped treatment, leaving $94.1 \%$ of the original cohort still on RRT. Table 1.9 shows the percentages on each

Table 1.8. Primary renal diagnosis RRT incidence rates (2011) per million population (unadjusted)

\begin{tabular}{|c|c|c|c|c|c|}
\hline Diagnosis & England & $\mathrm{N}$ Ireland & Scotland & Wales & UK \\
\hline Diabetes & 23.7 & 26.0 & 22.9 & 33.2 & 24.2 \\
\hline Glomerulonephritis $^{*}$ & 12.2 & 14.4 & 16.2 & 19.9 & 12.9 \\
\hline Pyelonephritis & 6.8 & 12.1 & 7.2 & 6.6 & 6.9 \\
\hline Hypertension & 7.3 & 5.0 & 4.9 & 3.8 & 6.8 \\
\hline Polycystic kidney & 6.9 & 8.3 & 8.5 & 5.2 & 7.0 \\
\hline Renal vascular disease & 5.7 & 12.7 & 10.6 & 12.2 & 6.7 \\
\hline Other & 16.6 & 18.2 & 9.4 & 14.0 & 15.9 \\
\hline Uncertain aetiology & 16.9 & 15.5 & 13.4 & 22.7 & 16.8 \\
\hline Data not available & 13.1 & 0.0 & 0.4 & 1.7 & 11.0 \\
\hline All & 109 & 112 & 93 & 119 & 108 \\
\hline
\end{tabular}

${ }^{\star}$ Presumed glomerulonephritis not biopsy proven has now been grouped into glomerulonephritis rather than into uncertain as in previous years

The overall rates per country may be slightly different to those in table 1.1 as those centres whose PRD data has not been used have been excluded from both the numerator and the denominator here 
Table 1.9. RRT modality at 90 days by centre (incident cohort $1 / 10 / 2010$ to 30/09/2011)

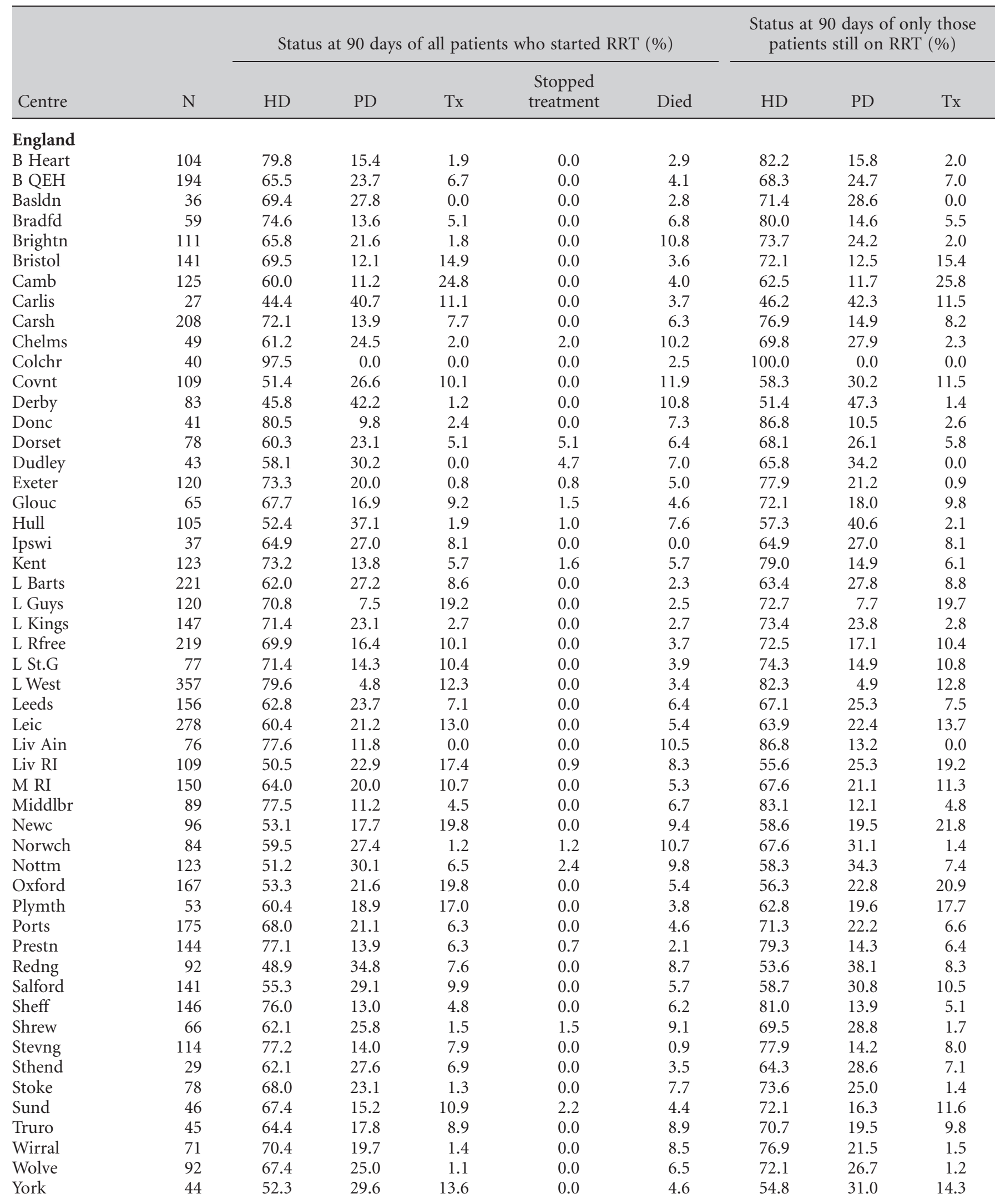


Table 1.9. Continued

\begin{tabular}{|c|c|c|c|c|c|c|c|c|c|}
\hline \multirow[b]{2}{*}{ Centre } & \multirow[b]{2}{*}{$\mathrm{N}$} & \multicolumn{5}{|c|}{ Status at 90 days of all patients who started RRT (\%) } & \multicolumn{3}{|c|}{$\begin{array}{c}\text { Status at } 90 \text { days of only those } \\
\text { patients still on RRT }(\%)\end{array}$} \\
\hline & & HD & PD & $\mathrm{Tx}$ & $\begin{array}{l}\text { Stopped } \\
\text { treatment }\end{array}$ & Died & HD & PD & $\mathrm{Tx}$ \\
\hline \multicolumn{10}{|l|}{ N Ireland } \\
\hline Antrim & 25 & 60.0 & 20.0 & 8.0 & 4.0 & 8.0 & 68.2 & 22.7 & 9.1 \\
\hline Ulster & 35 & 85.7 & 5.7 & 0.0 & 2.9 & 5.7 & 93.8 & 6.3 & 0.0 \\
\hline West NI & 35 & 77.1 & 17.1 & 2.9 & 0.0 & 2.9 & 79.4 & 17.7 & 2.9 \\
\hline \multicolumn{10}{|l|}{ Scotland } \\
\hline Abrdn & 51 & 82.4 & 11.8 & 0.0 & 0.0 & 5.9 & 87.5 & 12.5 & 0.0 \\
\hline Airdrie & 41 & 90.2 & 4.9 & 2.4 & 0.0 & 2.4 & 92.5 & 5.0 & 2.5 \\
\hline D \& Gall & 10 & 40.0 & 60.0 & 0.0 & 0.0 & 0.0 & 40.0 & 60.0 & 0.0 \\
\hline Inverns & 17 & 76.5 & 23.5 & 0.0 & 0.0 & 0.0 & 76.5 & 23.5 & 0.0 \\
\hline Klmarnk & 32 & 56.3 & 18.8 & 3.1 & 0.0 & 21.9 & 72.0 & 24.0 & 4.0 \\
\hline \multicolumn{10}{|l|}{ Wales } \\
\hline Bangor & 26 & 73.1 & 26.9 & 0.0 & 0.0 & 0.0 & 73.1 & 26.9 & 0.0 \\
\hline Cardff & 192 & 67.7 & 19.3 & 9.9 & 0.0 & 3.1 & 69.9 & 19.9 & 10.2 \\
\hline Swanse & 120 & 70.8 & 22.5 & 0.8 & 0.0 & 5.8 & 75.2 & 23.9 & 0.9 \\
\hline Wrexm & 26 & 65.4 & 19.2 & 7.7 & 0.0 & 7.7 & 70.8 & 20.8 & 8.3 \\
\hline England & 5,703 & 66.0 & 19.6 & 8.5 & 0.4 & 5.6 & 70.2 & 20.9 & 9.0 \\
\hline N Ireland & 197 & 76.1 & 14.7 & 4.6 & 1.0 & 3.6 & 79.8 & 15.4 & 4.8 \\
\hline Scotland & 485 & 75.1 & 14.9 & 2.9 & 0.2 & 7.0 & 80.9 & 16.0 & 3.1 \\
\hline Wales & 371 & 69.3 & 20.5 & 5.9 & 0.0 & 4.3 & 72.4 & 21.4 & 6.2 \\
\hline UK & 6,756 & 67.1 & 19.2 & 7.8 & 0.3 & 5.5 & 71.3 & 20.4 & 8.3 \\
\hline
\end{tabular}

treatment modality at 90 days both as percentages of all of those starting RRT and then of those still on treatment at 90 days. Expressed as percentages of the whole incident cohort, $67.1 \%$ were on HD at 90 days, $19.2 \%$ were on PD and $7.8 \%$ had received a transplant. Expressed as percentages of those still receiving RRT at 90 days, $71.3 \%$ were on HD, 20.4\% on PD and $8.3 \%$ had received a transplant. Last year it was reported that the percentage receiving peritoneal dialysis at 90 days had increased from the previous year for the first time since the start of the Renal Registry, this percentage further increased from 2010 to 2011 (from 19.2 to $20.4 \%$ ).

The percentage of patients on PD at 90 days increased greatly for Northern Ireland (from 6\% to 15\%) making it much closer to the percentages seen in the other countries. Figure 1.8 shows the modality breakdown with the HD patients further subdivided. Of those still on RRT at 90 days, $43 \%$ were treated with main centre HD and 28\% with satellite HD.

The percentage of incident patients who had died by 90 days varied considerably between centres $(0 \%$ to
$22 \%$, table 1.9). Differences in the definition of whether patients have acute or chronic renal failure may be a factor in this apparent variation along with possible differences in clinical practice.

The percentage of patients still on RRT at 90 days who had a functioning transplant at 90 days varied between

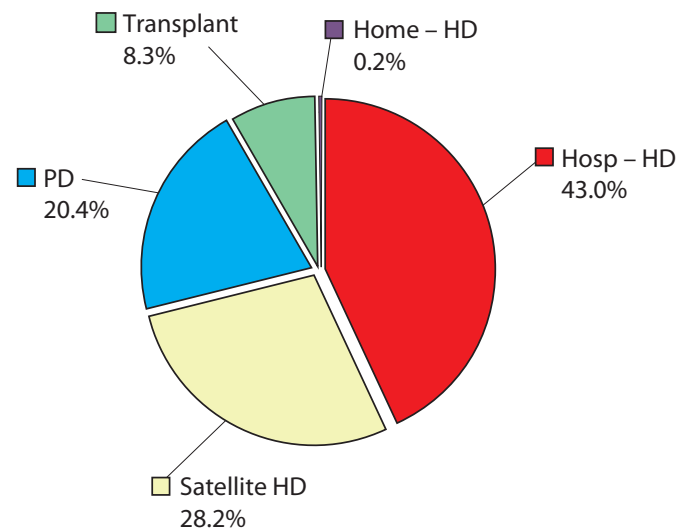

Fig. 1.8. RRT modality at 90 days (incident cohort $1 / 10 / 2010$ to 30/09/2011) 
centres from $0 \%$ to $26 \%$. The mean percentage of the incident cohort with a functioning transplant by 90 days was significantly greater in transplanting compared to non-transplanting centres $(11.4 \%$ vs. $4.4 \%$ : $\mathrm{p}<0.0001)$. One possible reason could be that some patients transplanted pre-emptively were attributed to the incident cohort of the transplanting centre rather than that of the referring centre (as mentioned earlier).

Table 1.10 gives the HD/PD breakdown for those incident patients on dialysis at 90 days. The breakdown is given by age group and overall. The percentage on PD at 90 days was about $60 \%$ higher in patients aged under 65 years than in older patients $(27.8 \%$ vs. $17.1 \%)$. This was a change from 2010 when the percentage on PD was twice as high in the younger group than in the older group. The percentage on PD fell slightly from 2010 to 2011 in the younger age group (28.2 to $27.8 \%$ ) but increased markedly in the over 65 age group $(14.0 \%$ to $17.1 \%)$. For the younger age group, four centres (Derby, Hull, Nottm, Sthend) had over twice the average percentage on PD. Derby also had over twice the average percentage on PD in the older age group.

The median age at start for those on HD at 90 days was 67.3 years compared with 60.2 years for PD. For $\mathrm{PD}$, this was an increase in median age at start of almost two years from 2010 to 2011. There were 11 centres where the percentage of patients treated with $\mathrm{PD}$ was the same as or higher in the over $65 \mathrm{~s}$ than the under 65s (compared with four centres for 2010).

\section{Modality change over time}

Table 1.11 gives the breakdown of status/treatment modality at four subsequent time points by initial treatment type for patients starting RRT in 2006. Fifty-four percent of patients who started on HD had died within five years of starting. This compared to $33 \%$ and $6 \%$ for those starting on PD or transplant respectively. Of those patients starting on $\mathrm{PD}, 92 \%$ were on $\mathrm{PD}$ at 90 days but this percentage dropped sharply at the later time points. In contrast, $90 \%$ of patients starting with

Table 1.10. Modality split of patients on dialysis at 90 days (incident cohort $1 / 10 / 2010$ to $30 / 09 / 2011$ )

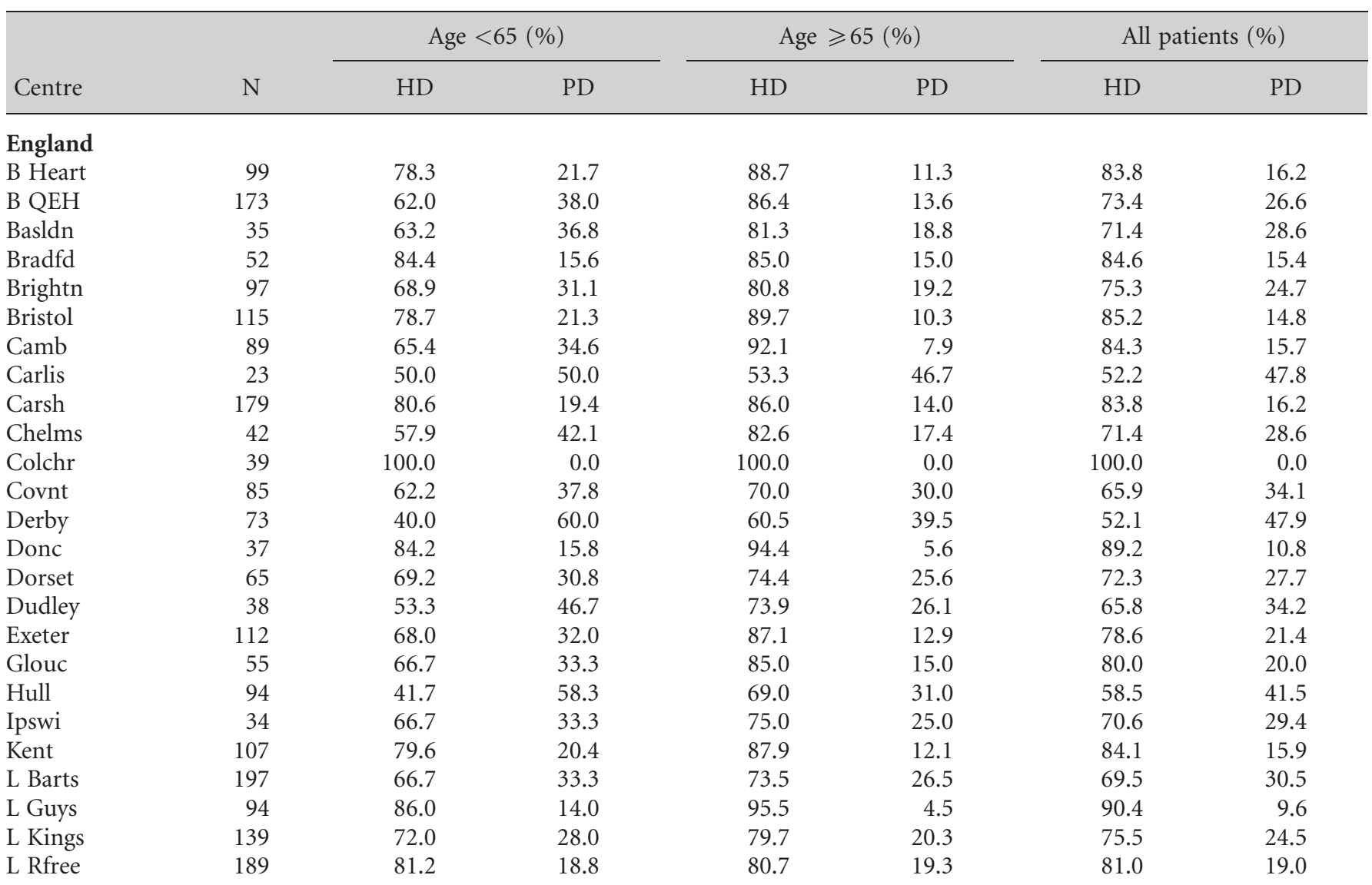


Table 1.10. Continued

\begin{tabular}{|c|c|c|c|c|c|c|c|}
\hline \multirow[b]{2}{*}{ Centre } & \multirow[b]{2}{*}{$\mathrm{N}$} & \multicolumn{2}{|c|}{ Age $<65(\%)$} & \multicolumn{2}{|c|}{ Age $\geqslant 65(\%)$} & \multicolumn{2}{|c|}{ All patients (\%) } \\
\hline & & HD & PD & HD & PD & HD & PD \\
\hline L St.G & 66 & 75.0 & 25.0 & 93.3 & 6.7 & 83.3 & 16.7 \\
\hline L West & 301 & 96.8 & 3.2 & 91.7 & 8.3 & 94.4 & 5.6 \\
\hline Leeds & 135 & 60.6 & 39.4 & 84.1 & 15.9 & 72.6 & 27.4 \\
\hline Leic & 227 & 74.5 & 25.5 & 73.6 & 26.4 & 74.0 & 26.0 \\
\hline Liv Ain & 68 & 82.8 & 17.2 & 89.7 & 10.3 & 86.8 & 13.2 \\
\hline Liv RI & 80 & 54.5 & 45.5 & 86.1 & 13.9 & 68.8 & 31.3 \\
\hline M RI & 126 & 71.4 & 28.6 & 82.1 & 17.9 & 76.2 & 23.8 \\
\hline Middlbr & 79 & 89.5 & 10.5 & 85.4 & 14.6 & 87.3 & 12.7 \\
\hline Newc & 68 & 70.3 & 29.7 & 80.6 & 19.4 & 75.0 & 25.0 \\
\hline Norwch & 73 & 60.6 & 39.4 & 75.0 & 25.0 & 68.5 & 31.5 \\
\hline Nottm & 100 & 42.9 & 57.1 & 73.8 & 26.2 & 63.0 & 37.0 \\
\hline Oxford & 125 & 58.2 & 41.8 & 86.2 & 13.8 & 71.2 & 28.8 \\
\hline Plymth & 42 & 62.5 & 37.5 & 84.6 & 15.4 & 76.2 & 23.8 \\
\hline Ports & 156 & 68.8 & 31.2 & 83.5 & 16.5 & 76.3 & 23.7 \\
\hline Prestn & 131 & 80.6 & 19.4 & 89.1 & 10.9 & 84.7 & 15.3 \\
\hline Redng & 77 & 51.2 & 48.8 & 67.6 & 32.4 & 58.4 & 41.6 \\
\hline Salford & 119 & 52.4 & 47.6 & 80.4 & 19.6 & 65.5 & 34.5 \\
\hline Sheff & 130 & 86.4 & 13.6 & 84.4 & 15.6 & 85.4 & 14.6 \\
\hline Shrew & 58 & 50.0 & 50.0 & 83.3 & 16.7 & 70.7 & 29.3 \\
\hline Stevng & 104 & 81.1 & 18.9 & 88.2 & 11.8 & 84.6 & 15.4 \\
\hline Sthend & 26 & 42.9 & 57.1 & 78.9 & 21.1 & 69.2 & 30.8 \\
\hline Stoke & 71 & 65.4 & 34.6 & 80.0 & 20.0 & 74.6 & 25.4 \\
\hline Sund & 38 & 72.7 & 27.3 & 93.8 & 6.3 & 81.6 & 18.4 \\
\hline Truro & 37 & 78.9 & 21.1 & 77.8 & 22.2 & 78.4 & 21.6 \\
\hline Wirral & 64 & 69.7 & 30.3 & 87.1 & 12.9 & 78.1 & 21.9 \\
\hline Wolve & 85 & 73.0 & 27.0 & 72.9 & 27.1 & 72.9 & 27.1 \\
\hline York & 36 & 60.0 & 40.0 & 68.8 & 31.3 & 63.9 & 36.1 \\
\hline \multicolumn{8}{|l|}{ N Ireland } \\
\hline Antrim & 20 & 66.7 & 33.3 & 78.6 & 21.4 & 75.0 & 25.0 \\
\hline Belfast & 65 & 83.3 & 16.7 & 85.7 & 14.3 & 84.6 & 15.4 \\
\hline Newry & 29 & 80.0 & 20.0 & 78.9 & 21.1 & 79.3 & 20.7 \\
\hline Ulster & 32 & 85.7 & 14.3 & 100.0 & 0.0 & 93.8 & 6.3 \\
\hline West NI & 33 & 77.8 & 22.2 & 86.7 & 13.3 & 81.8 & 18.2 \\
\hline \multicolumn{8}{|l|}{ Scotland } \\
\hline Abrdn & 48 & 82.6 & 17.4 & 92.0 & 8.0 & 87.5 & 12.5 \\
\hline Airdrie & 39 & 92.9 & 7.1 & 100.0 & 0.0 & 94.9 & 5.1 \\
\hline D \& Gall & 10 & 66.7 & 33.3 & 0.0 & 100.0 & 40.0 & 60.0 \\
\hline Dundee & 55 & 91.3 & 8.7 & 90.6 & 9.4 & 90.9 & 9.1 \\
\hline Dunfn & 41 & 75.0 & 25.0 & 85.7 & 14.3 & 80.5 & 19.5 \\
\hline Edinb & 61 & 80.0 & 20.0 & 81.0 & 19.0 & 80.3 & 19.7 \\
\hline Glasgw & 141 & 80.3 & 19.7 & 86.7 & 13.3 & 83.7 & 16.3 \\
\hline Inverns & 17 & 57.1 & 42.9 & 90.0 & 10.0 & 76.5 & 23.5 \\
\hline Klmarnk & 24 & 80.0 & 20.0 & 71.4 & 28.6 & 75.0 & 25.0 \\
\hline \multicolumn{8}{|l|}{ Wales } \\
\hline Bangor & 26 & 64.3 & 35.7 & 83.3 & 16.7 & 73.1 & 26.9 \\
\hline Cardff & 167 & 73.8 & 26.3 & 81.6 & 18.4 & 77.8 & 22.2 \\
\hline Swanse & 112 & 58.3 & 41.7 & 89.1 & 10.9 & 75.9 & 24.1 \\
\hline Wrexm & 22 & 60.0 & 40.0 & 91.7 & 8.3 & 77.3 & 22.7 \\
\hline England & 4,884 & 71.3 & 28.7 & 82.4 & 17.6 & 77.1 & 22.9 \\
\hline N Ireland & 179 & 80.8 & 19.2 & 86.1 & 13.9 & 83.8 & 16.2 \\
\hline Scotland & 436 & 81.6 & 18.4 & 85.4 & 14.6 & 83.5 & 16.5 \\
\hline Wales & 333 & 67.5 & 32.5 & 85.5 & 14.5 & 77.2 & 22.8 \\
\hline UK & 5,832 & 72.2 & 27.8 & 82.9 & 17.1 & 77.8 & 22.2 \\
\hline
\end{tabular}


Table 1.11. Initial and subsequent modalities for patients starting RRT in 2006

\begin{tabular}{|c|c|c|c|c|c|c|}
\hline \multirow[b]{2}{*}{ First treatment } & \multirow[b]{2}{*}{$\mathrm{N}$} & \multirow[b]{2}{*}{ Later modality } & \multicolumn{4}{|c|}{ Percentage } \\
\hline & & & 90 days & 1 year & 3 years & 5 years \\
\hline \multirow{3}{*}{$\mathrm{HD}$} & & $\mathrm{PD}$ & 3 & 4 & 2 & 1 \\
\hline & & Transplant & 0 & 3 & 10 & 15 \\
\hline & & Other ${ }^{\star}$ & 1 & 1 & 1 & 1 \\
\hline \multirow[t]{5}{*}{ PD } & 1,267 & $\mathrm{HD}$ & 4 & 15 & 22 & 19 \\
\hline & & $\mathrm{PD}$ & 92 & 68 & 31 & 12 \\
\hline & & Transplant & 1 & 10 & 26 & 35 \\
\hline & & Other ${ }^{*}$ & 0 & 1 & 1 & 1 \\
\hline & & Died & 2 & 7 & 21 & 33 \\
\hline
\end{tabular}

${ }^{\star}$ Other e.g. stopped treatment

a transplant continued to be transplant patients after 5 years.

\section{Renal function at the time of starting RRT}

The mean eGFR at initiation of RRT in 2011 was $8.7 \mathrm{ml} / \mathrm{min} / 1.73 \mathrm{~m}^{2}$. This was highest in the $65-74$ and $75-84$ age groups at about $8.9 \mathrm{ml} / \mathrm{min} / 1.73 \mathrm{~m}^{2}$ (figure 1.9). By contrast, in the United States 54\% of patients starting RRT in 2009 had an eGFR greater than $10 \mathrm{ml} / \mathrm{min} / 1.73 \mathrm{~m}^{2}$ [4].

Figure 1.10 shows serial data from centres reporting annually to the UKRR since 2002. For HD patients,

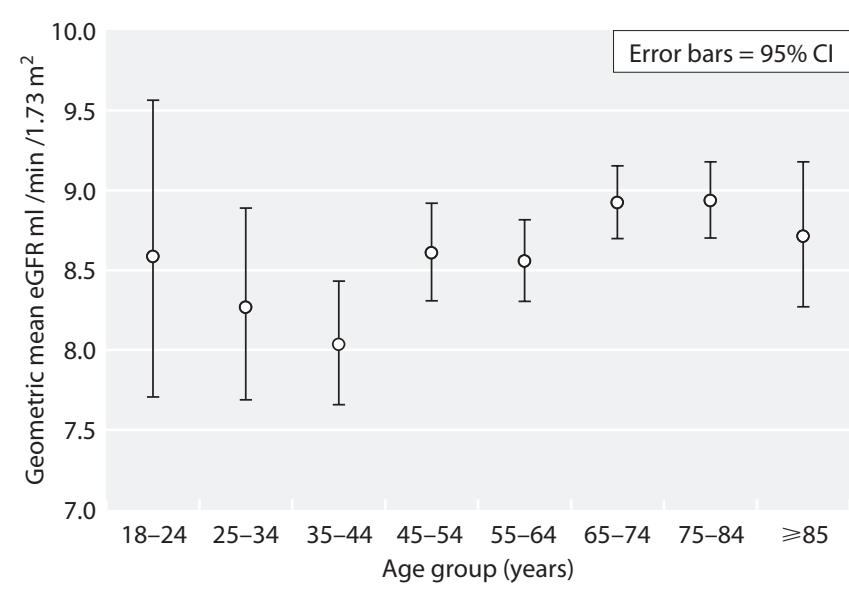

Fig. 1.9. Geometric mean eGFR at start of RRT (2011) by age group average eGFR at start of RRT in 2011 was similar to that for 2010. For the six years prior to 2011 there was higher average eGFR at start of RRT for PD than HD patients but there was a small fall in the eGFR for PD patients for 2011 bringing the average just below that for HD patients.

Some caution should be applied to the analysis of eGFR at the start of RRT as a review of pre-RRT biochemistry in nine renal centres revealed that up to $18 \%$ of patients may have had an incorrect date of starting RRT allocated and thus, the eGFR used for analysis may have been taken whilst they were already

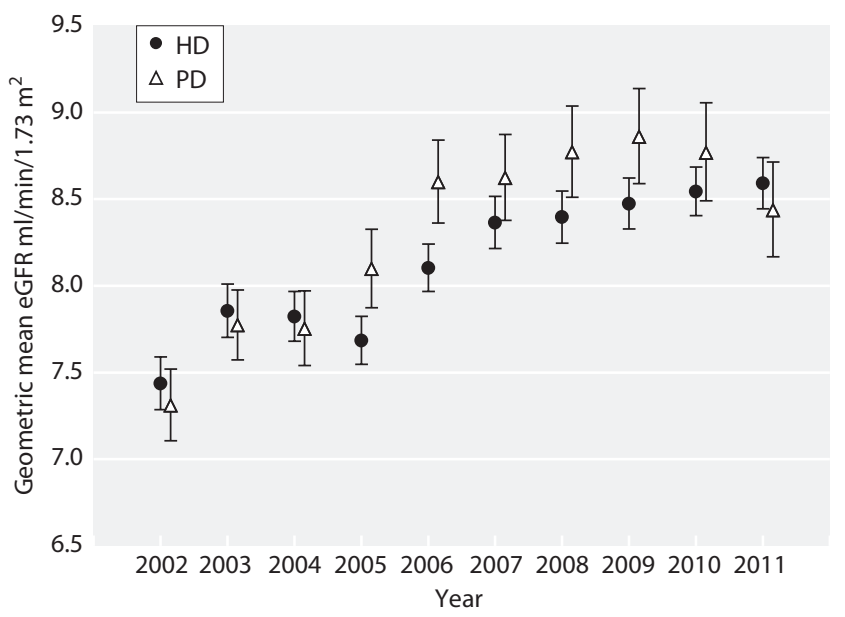

Fig. 1.10. eGFR on starting RRT 2002 to 2011, PD and HD (restricted to centres reporting since 2002)

Nephron Clin Pract 2013;123(suppl1):1-28 
receiving RRT. For details see the 12th Annual Report chapter 13: The UK Renal Registry Advanced CKD Study 2009 [5].

\section{Late presentation and delayed referral of incident patients}

\section{Introduction}

Late presentation to a nephrologist is regarded as a negative aspect in renal centres. It can be defined in a number of ways as it has a range of possible causes. There are many patients with chronic kidney disease who are regularly monitored in primary or secondary care and whose referral to nephrology services is delayed (delayed or late referral). In contrast, other patients present late to medical services due to no particular deficiency in the service; those with either such slowly progressive disease as to have remained asymptomatic for many years or the opposite with rapidly progressive glomerulonephritis. The main analyses presented here do not differentiate between these groups and include any patient first seen by renal services within 90 days of starting RRT as 'late presentation'.

One analysis (shown in table 1.13) attempts to capture 'late referrals'. In this table the percentage presenting within 90 days of starting RRT is shown after excluding an acute renal disease group. This group is made up of those people with conditions likely to present with rapidly deteriorating renal function: crescentic glomerulonephritis (type I, II, III), nephropathy (interstitial) due to cis-platinum, renal vascular disease due to malignant hypertension, renal vascular disease due to polyarteritis, Wegener's granulomatosis, cryoglobulinemic glomerulonephritis, myelomatosis/light chain deposit disease, Goodpasture's Syndrome, systemic sclerosis, haemolytic ureaemic syndrome (including Moschcowitz syndrome), multi-system disease - other, tubular necrosis (irreversible) or cortical necrosis, Balkan nephropathy, kidney tumour and traumatic or surgical loss of kidney.

\section{Methods}

Data were included from all incident patients in the years 2010 to 2011. The date first seen in a renal centre and the date of starting RRT were used to define the late presenting cohort. A small amount of data were excluded because of actual or potential inconsistencies. Only data from those centres with $75 \%$ or more completeness for the relevant year were used. Data were excluded for centres for any year where $10 \%$ or more of the patients were reported to have started RRT on the same date as the first presentation. This was because investigation has shown that this is likely due to misunderstanding on the part of the renal centres resulting in incorrect recording of data. After these exclusions, data on 9,118 patients were available for analysis. Presentation times of 90 days or more were defined as early presentation and times of less than 90 days were defined as late presentation.

\section{Results}

Table 1.12 shows the percentage completeness of data for 2010 and 2011. Last year's report showed a big improvement in the reporting of presentation time data from 2009 to 2010 (from about 50\% to about $80 \%$ complete). The completeness for 2011 was again about $80 \%$. The 2010-2011 cohort available for analysis was therefore substantially larger than the 2009-2010 cohort used in last year's report. Nevertheless, a two year cohort is again used for most of the analyses in order to make the late presentation percentages more reliably estimated and to allow these to be shown for subgroups of patients.

\section{Late presentation by centre}

Figure 1.11 shows that late presentation varied between centres from $9-35 \%$ in patients starting RRT in 2010 to 2011. The overall rate of late presentation was $20.1 \%$ and was $14.9 \%$ once those people with diseases likely to present acutely were excluded. Table 1.13 shows the overall percentage presenting late for the combined 2010-2011 incident cohort, the percentages presenting late amongst those patients defined as not having an 'acute diagnosis' and the percentages amongst nondiabetics (as PRD).

\section{Late presentation in 2011 and the trend over time}

There has been a steady decline nationally in the proportion of patients presenting late to renal services, with some centres achieving $<10 \%$ late presentation rates. This may be a consequence of the National CKD guidelines published by the Medical and GP Royal Colleges [6], the Quality and Outcomes Framework (QOF) initiative (www.dh.gov.uk) raising awareness of CKD amongst non-nephrologists and the introduction of estimated GFR reporting.

In 2011, 67.3\% of incident patients presented over a year before they needed to start RRT. There were $8.4 \%$ of patients presenting within 6-12 months, $4.7 \%$ within 3-6 months and $19.6 \%$ within 3 months. These figures have remained stable over the last 2 years. Figure 1.12 shows this breakdown by year for those 18 centres supplying data over $75 \%$ complete for each of 
Table 1.12. Percentage completeness of time of presentation data ( 2010 and 2011 incident RRT patients) by centre

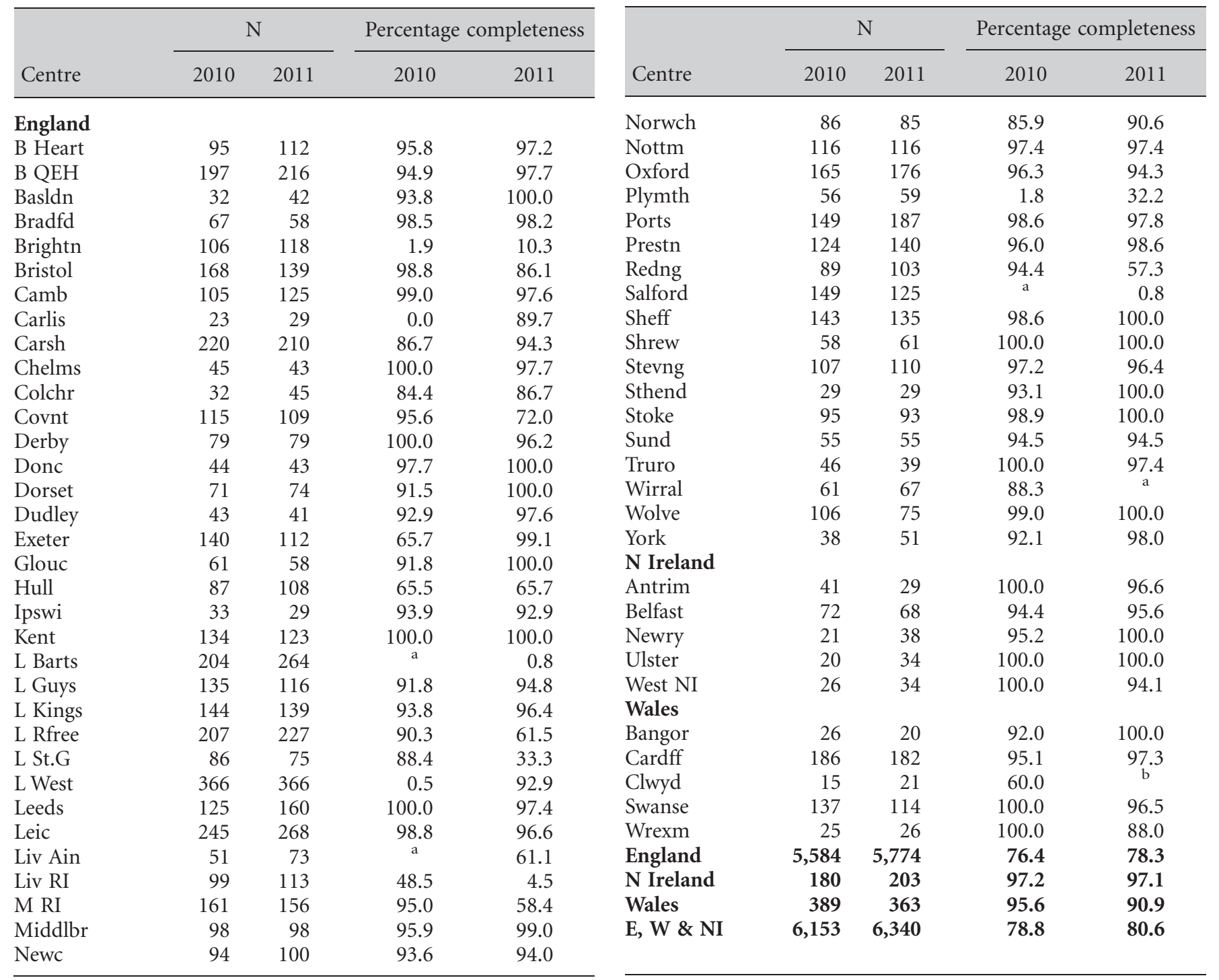

a data not shown as $>10 \%$ of patients reported as starting RRT on the same date as first presentation

${ }^{\mathrm{b}}$ Clwyd not shown for 2011 as less than 10 patients with full data

Date first seen by a nephrologist has not been collected from the Scottish Renal Registry and so Scottish centres were excluded from these analyses

the last six years. The percentage of patients presenting late in these centres fell steadily until 2009 alongside an increase in those presenting 12 months or more before starting RRT. There was less change between 2009 and 2011.

\section{Age and late presentation}

In the 2010 to 2011 cohort, patients who presented late were not significantly older or younger than patients who presented earlier ( $>90$ days before RRT initiation) (median age 65.3 vs. 65.4 years: $p=0.3$ ). Except for the two youngest age groups, the median duration of pre-RRT care did not vary greatly with age (figure 1.13).

\section{Gender and late presentation}

In the 2010 to 2011 cohort, there was no significant difference in the ratio of males to females by time of presentation (male:female ratio 1.72 in early presentation, 1.81 in late presentation, $\mathrm{p}=0.32$ ).

Ethnicity, social deprivation and late presentation

In the 2010 to 2011 cohort, the percentage of South Asian and Black patients presenting late $(<90$ days) 


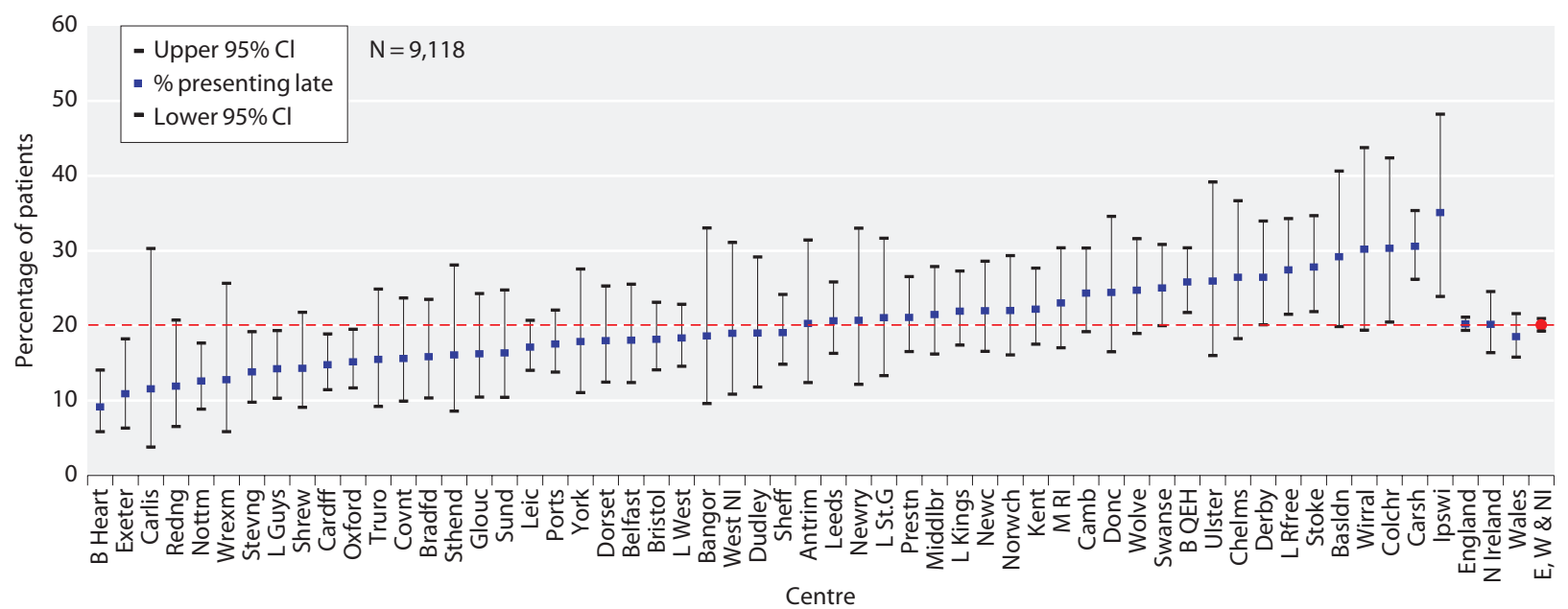

Fig. 1.11. Percentage presenting late (2010/2011)

was significantly lower than in Whites (17.6\% vs. $20.3 \%$ : $\mathrm{p}=0.02)$. The high incidence of diabetes in non-Whites (as discussed below, patients with diabetes tended to present earlier) explains most of the difference in presentation time between the ethnic groups. When patients with diabetes were excluded, the percentages presenting late ( $<90$ days) became $22.8 \%$ in South Asian and Black patients vs. $23.3 \%$ in Whites $(p=0.8)$. There was no relationship between social deprivation and presentation pattern.

\section{Primary renal disease and late presentation}

In the 2010 to 2011 cohort, late presentation differed significantly between primary renal diagnoses (Chi-squared test $\mathrm{p}<0.0001$ ) (table 1.14). Patients in the acute group or with data not available had high rates of late presentation. Those with diabetes and pyelonephritis or adult polycystic kidney disease had low rates. There was a notable decline in the proportion of diabetics presenting late up until 2007. Since then the proportion has been stable. The decline seen earlier likely reflects national initiatives to screen patients with diabetes for proteinuria and falling GFR.

\section{Modality and late presentation}

In the 2010 to 2011 cohort, late presentation was associated with initial modality. The percentage of patients

Table 1.13 Percentage of patients presenting to a nephrologist less than 90 days before RRT initiation (2010-2011 incident patients) by centre

\begin{tabular}{|c|c|c|c|c|c|}
\hline \multirow[b]{2}{*}{ Centre } & \multirow[b]{2}{*}{$\mathrm{N}$ with data } & \multicolumn{4}{|c|}{ Percentage presenting late } \\
\hline & & Overall & $(95 \% \mathrm{CI})$ & Non-acute ${ }^{*}$ & Non-diab PRD \\
\hline \multicolumn{6}{|l|}{ England } \\
\hline B Heart & 197 & 9.1 & $(5.8-14.0)$ & 7.3 & 13.5 \\
\hline B QEH & 395 & 25.8 & $(21.8-30.4)$ & 21.7 & 26.0 \\
\hline Basldn & 72 & 29.2 & $(19.9-40.6)$ & 22.7 & 32.7 \\
\hline Bradfd & 120 & 15.8 & $(10.3-23.5)$ & 14.2 & 17.1 \\
\hline Bristol & 281 & 18.2 & $(14.1-23.1)$ & 13.6 & 20.2 \\
\hline Camb & 226 & 24.3 & $(19.2-30.4)$ & & \\
\hline Carlis & 26 & 11.5 & $(3.8-30.3)$ & 13.6 & 5.9 \\
\hline Carsh & 386 & 30.6 & $(26.2-35.4)$ & 24.1 & 33.5 \\
\hline Chelms & 87 & 26.4 & $(18.2-36.7)$ & 21.1 & 25.7 \\
\hline Colchr & 66 & 30.3 & $(20.5-42.4)$ & 25.0 & 29.2 \\
\hline Covnt & 109 & 15.6 & $(9.9-23.7)$ & 11.2 & 16.8 \\
\hline Derby & 155 & 26.5 & $(20.1-34.0)$ & 18.5 & 32.8 \\
\hline Donc & 86 & 24.4 & $(16.5-34.6)$ & 18.4 & 29.9 \\
\hline Dorset & 139 & 18.0 & $(12.5-25.3)$ & 14.1 & 20.9 \\
\hline Dudley & 79 & 19.0 & $(11.8-29.1)$ & 17.1 & 24.1 \\
\hline
\end{tabular}


Table 1.13 Continued

\begin{tabular}{|c|c|c|c|c|c|}
\hline \multirow[b]{2}{*}{ Centre } & \multirow[b]{2}{*}{$\mathrm{N}$ with data } & \multicolumn{4}{|c|}{ Percentage presenting late } \\
\hline & & Overall & $(95 \% \mathrm{CI})$ & Non-acute ${ }^{\star}$ & Non-diab PRD \\
\hline Glouc & 111 & 16.2 & $(10.5-24.3)$ & 11.3 & 19.3 \\
\hline Ipswi & 57 & 35.1 & $(23.9-48.2)$ & 34.6 & 44.4 \\
\hline Kent & 257 & 22.2 & $(17.5-27.7)$ & 15.2 & 25.7 \\
\hline L Rfree & 186 & 27.4 & $(21.5-34.3)$ & 24.4 & 28.2 \\
\hline L St.G & 76 & 21.1 & $(13.3-31.6)$ & 15.4 & 24.1 \\
\hline L West & 338 & 18.3 & $(14.6-22.8)$ & 14.9 & 21.9 \\
\hline Leeds & 276 & 20.7 & $(16.3-25.8)$ & 14.8 & 24.2 \\
\hline Leic & 491 & 17.1 & $(14.0-20.7)$ & 9.7 & 20.1 \\
\hline Nottm & 222 & 12.6 & $(8.9-17.7)$ & 10.3 & 14.9 \\
\hline Oxford & 323 & 15.2 & $(11.7-19.5)$ & 11.4 & 17.7 \\
\hline Ports & 325 & 17.5 & $(13.8-22.1)$ & 10.0 & 19.7 \\
\hline Prestn & 256 & 21.1 & $(16.5-26.5)$ & 15.3 & 22.7 \\
\hline Redng & 84 & 11.9 & $(6.5-20.7)$ & 8.7 & 13.6 \\
\hline Sheff & 273 & 19.1 & $(14.8-24.1)$ & 12.3 & 22.5 \\
\hline Shrew & 119 & 14.3 & $(9.1-21.8)$ & 10.4 & 16.9 \\
\hline Stevng & 210 & 13.8 & $(9.8-19.2)$ & 9.8 & 17.4 \\
\hline Sthend & 56 & 16.1 & $(8.6-28.1)$ & 12.8 & 19.6 \\
\hline Stoke & 187 & 27.8 & $(21.9-34.7)$ & 21.6 & 32.4 \\
\hline Sund & 104 & 16.4 & $(10.4-24.7)$ & 11.0 & 19.7 \\
\hline Truro & 84 & 15.5 & $(9.2-24.9)$ & 14.1 & 20.0 \\
\hline Ulster & 54 & 25.9 & $(16.0-39.2)$ & 20.0 & 28.2 \\
\hline West NI & 58 & 19.0 & $(10.8-31.1)$ & 17.0 & 18.8 \\
\hline \multicolumn{6}{|l|}{ Wales } \\
\hline Bangor & 43 & 18.6 & $(9.6-33.0)$ & 16.7 & 20.6 \\
\hline Cardff & 352 & 14.8 & $(11.4-18.9)$ & 11.7 & 18.0 \\
\hline Swanse & 244 & 25.0 & $(20.0-30.8)$ & 18.2 & 30.2 \\
\hline Wrexm & 47 & 12.8 & $(5.9-25.6)$ & 11.6 & 17.7 \\
\hline England & 8,060 & 20.2 & $(19.4-21.1)$ & 15.0 & 23.0 \\
\hline N Ireland & 372 & 20.2 & $(16.4-24.6)$ & 14.6 & 21.6 \\
\hline Wales & 686 & 18.5 & $(15.8-21.6)$ & 14.3 & 22.6 \\
\hline $\mathrm{E}, \mathrm{W} \& \mathrm{NI}$ & 9,118 & 20.1 & $(19.3-20.9)$ & 14.9 & 22.9 \\
\hline$(\min , \max )$ & & $(9.1-35.1)$ & & $(7.3-34.6)$ & $(5.9-44.4)$ \\
\hline (IQR) & & $(15.9-24.4)$ & & $(11.4-18.4)$ & $(18.8-26.3)$ \\
\hline
\end{tabular}

Blank cells - data for PRD not used due to high \% with uncertain aetiology

${ }^{*}$ Non-acute group excludes crescentic (extracapillary) glomerulonephritis (type I, II, III), nephropathy (interstitial) due to cis-platinum, renal vascular disease due to malignant hypertension, renal vascular disease due to polyarteritis, Wegener's granulomatosis, cryoglobulinemic glomerulonephritis, myelomatosis/light chain deposit disease, Goodpasture's Syndrome, systemic sclerosis (scleroderma), haemolytic ureaemic syndrome (including Moschcowitz syndrome), multi-system disease - other, tubular necrosis (irreversible) or cortical necrosis, Balkan nephropathy, kidney tumour, and traumatic or surgical loss of kidney 


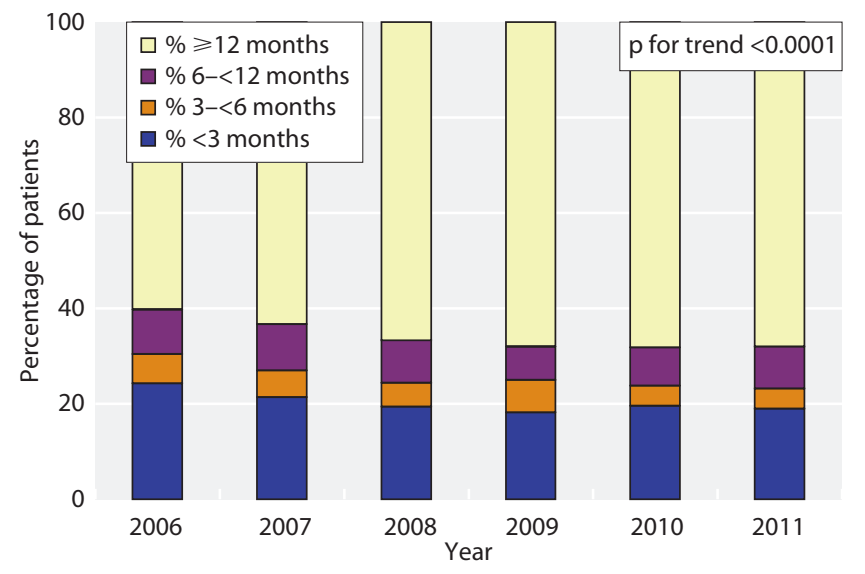

Fig. 1.12. Late presentation rate by year (2006-2011)

Restricted to centres reporting continuous data for 2006-2011

whose first modality was PD was significantly lower in the late presentation group than in those presenting earlier (9.1\% vs. $21.6 \%$ : p < 0.0001). By 90 days after RRT initiation this difference was reduced, although it was still highly significant $(12.2 \%$ vs. $21.6 \%$ : $\mathrm{p}<0.0001)$.

\section{Comorbidity and late presentation}

In the 2010 to 2011 cohort, the percentage of patients who were assessed as having no comorbidity was roughly the same in those who presented late and those presenting earlier $(45.1 \%$ vs. $46.9 \%: p=0.3)$. Ischaemic heart disease, cerebrovascular disease and peripheral vascular disease were significantly less common in the group presenting late (table 1.15). Malignancy was significantly more common in those presenting late; perhaps because of the potential for rapid decline in renal function in this group.

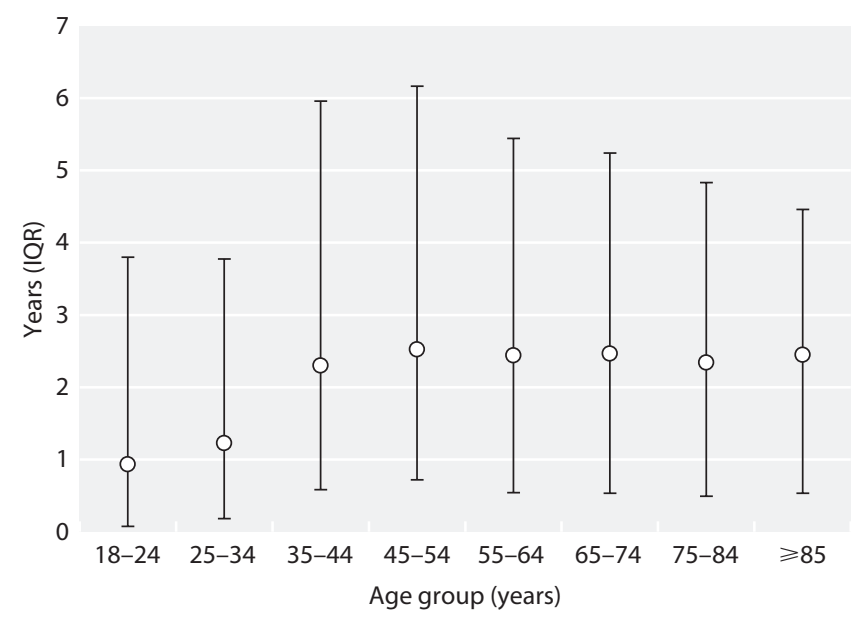

Fig. 1.13. Median duration of pre-RRT care by age group (incident patients 2010-2011)
Table 1.14. Late presentation by primary renal diagnosis (20102011 incident patients)

\begin{tabular}{lrrr}
\hline & & \multicolumn{2}{c}{ Late presentation } \\
\cline { 3 - 4 } Diagnosis & $\mathrm{N}$ & $\mathrm{N}$ & $\%$ \\
\hline Uncertain aetiology & 1,440 & 316 & 21.9 \\
Diabetes & 2,044 & 201 & 9.8 \\
Glomerulonephritis & 1,071 & 153 & 14.3 \\
Other identified category & 714 & 160 & 22.4 \\
Polycystic kidney or & 1,209 & 126 & 10.4 \\
pyelonephritis & & & \\
Renal vascular disease & 1,069 & 167 & 15.6 \\
Acute group & 816 & 457 & 56.0 \\
Data not available & 459 & 172 & 37.5 \\
\hline \multirow{2}{*}{ Presumed } & &
\end{tabular}

${ }^{\star}$ Presumed glomerulonephritis not biopsy proven has now been grouped into glomerulonephritis rather than into uncertain as in previous years

Unlike elsewhere in the report, the RVD group includes hypertension and polycystic and pyelonephritis are grouped together

Acute group includes crescentic (extracapillary) glomerulonephritis (type I, II, III), nephropathy (interstitial) due to cis-platinum, renal vascular disease due to malignant hypertension, renal vascular disease due to polyarteritis, Wegener's granulomatosis, cryoglobulinemic glomerulonephritis, myelomatosis/light chain deposit disease, Goodpasture's Syndrome, systemic sclerosis (scleroderma), haemolytic ureaemic syndrome (including Moschcowitz syndrome), multi-system disease - other, tubular necrosis (irreversible) or cortical necrosis, Balkan nephropathy, kidney tumour, and traumatic or surgical loss of kidney

\section{Haemoglobin and late presentation}

In the 2010 to 2011 cohort, patients presenting late had a significantly lower average haemoglobin concentration at RRT initiation than patients presenting earlier (9.4 vs. $10.3 \mathrm{~g} / \mathrm{dl}: \mathrm{p}<0.0001)$. This may reflect inadequate pre-dialysis care with limited anaemia management, but alternatively those presenting late may be more likely to have anaemia because of multisystem disease or inter-current illness. More detailed analyses of haemoglobin at start of RRT and late

Table 1.15. Percentage prevalence of specific comorbidities amongst patients presenting late $(<3$ months) compared with those presenting early ( $\geqslant 3$ months) (2010-2011 incident patients)

\begin{tabular}{lccc}
\hline Comorbidity & $<3$ months & $\geqslant 3$ months & p-value \\
\hline Ischaemic heart disease & 16.8 & 20.9 & 0.004 \\
Cerebrovascular disease & 7.9 & 10.3 & 0.02 \\
Peripheral vascular disease & 7.7 & 12.2 & $<0.0001$ \\
Diabetes (not a cause of ERF) & 8.0 & 9.2 & 0.2 \\
Liver disease & 3.6 & 2.7 & 0.1 \\
Malignancy & 19.2 & 11.0 & $<0.0001$ \\
COPD & 7.9 & 7.0 & 0.3 \\
Smoking & 14.6 & 13.4 & 0.3 \\
\hline
\end{tabular}




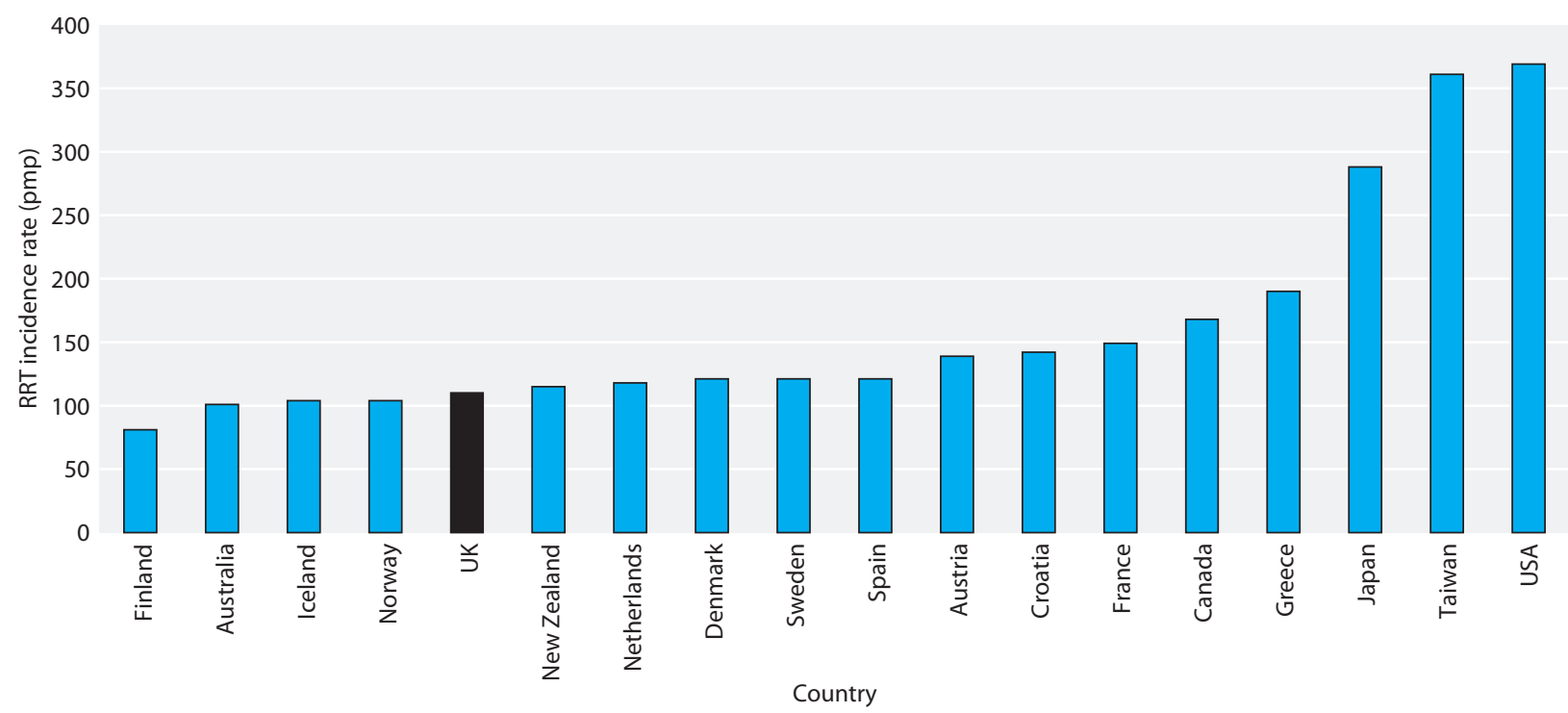

Fig. 1.14. International comparison of RRT incidence rates in 2010 Non UK data from USRDS

presentation can be found in chapter 6: Haemoglobin, Ferritin and Erythropoietin amongst UK Adult Dialysis Patients in 2011: national and centre-specific analyses.

eGFR at start of RRT and late presentation

In the 2010 to 2011 cohort, eGFR at start of RRT was significantly lower in patients presenting late than those presenting earlier $\left(8.0\right.$ vs. $8.9 \mathrm{ml} / \mathrm{min} / 1.73 \mathrm{~m}^{2}$ : $\mathrm{p}<0.0001)$.

\section{Survival of incident patients}

See chapter 5: Survival and Causes of Death of UK Adult Patients on Renal Replacement Therapy in 2011.

\section{International comparisons}

Figure 1.14 shows the crude RRT incidence rates (including children) for 2010 for several countries. The data is from the USRDS; 2010 was the latest year available at time of writing. The UK incidence rate was similar to many other Northern European countries and Australia and New Zealand but remains markedly lower than other countries, most notably Greece, Japan, Taiwan and the USA. These differences are likely to be due to the rate of advanced kidney disease in these populations as well as lower mortality from competing risks for RRT, such as cardiovascular disease in southern Europe and the Far East. The healthcare system in use in these countries may also influence RRT incidence.

\section{Summary}

RRT incidence rates for 2011 were similar to 2010 for England and for the UK as a whole. At least partly because of the smaller numbers involved, rates have been more variable over the last few years for Northern Ireland, Scotland and Wales. Wales continues to have the highest incidence rate. There remain large centre variations in incidence rates for RRT. There was a further increase from 2010 to 2011 in the percentage on PD at 90 days. Significant numbers of patients continue to present late to renal centres.

Conflicts of interest: none

\section{Acknowledgements}

The Registry would like to acknowledge the significant contribution made by Andy Judge, Dan Ford, David Ansell, Charlie Tomson, Paul Roderick and Yoav BenShlomo who developed the methodology for estimating catchment populations for England. 


\section{References}

1 Castledine, C.I., et al., How much of the regional variation in RRT incidence rates within the UK is explained by the health needs of the general population? Nephrology Dialysis Transplantation, 2012. 27(10): p. 3943-3950

2 Kuan, Y., et al., GFR prediction using the MDRD and Cockcroft and Gault equations in patients with end-stage renal disease. Nephrology Dialysis Transplantation, 2005. 20(11): p. 2394-2401

3 http://www.ons.gov.uk/ons/rel/ethnicity/focus-on-ethnicity-and-identity/ focus-on-ethnicity-and-identity-summary-report/focus-on-ethnicity-andidentity-summary-report.pdf

4 U.S. Renal Data System, USRDS 2011 Annual Data Report: Atlas of Chronic Kidney Disease and End-Stage Renal Disease in the United
States, National Institutes of Health, National Institute of Diabetes and Digestive and Kidney Diseases, Bethesda, MD, 2011. Publications based upon USRDS data reported here or supplied upon request must include this citation and the following notice: The data reported here have been supplied by the United States Renal Data System (USRDS)

5 Ford DJ, Fogarty DG, Steenkamp R, Tomson CRV, Ben-Shlomo Y, Ansell D. Chapter 13: The UK Renal Registry Advanced CKD Study: frequency of incorrect reporting of date of start of RRT. Nephron Clinical Practice; 115(Suppl. 1):c271-c78

6 http://www.renal.org/CKDguide/full/UKCKDfull.pdf 